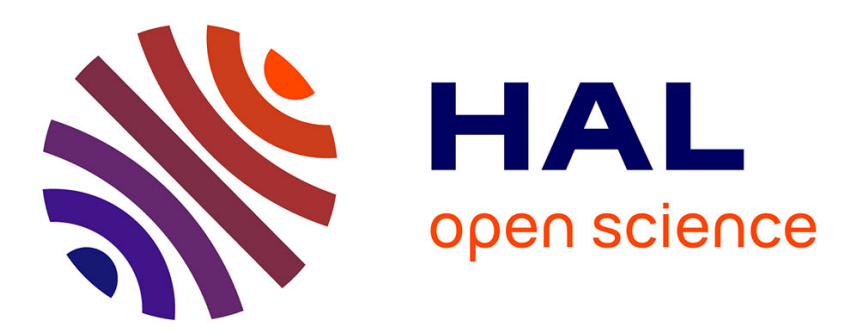

\title{
A critical review on thermal conductivity enhancement of graphene-based nanofluids
}

Mauricio Pavía, Khoder Alajami, Patrice Estellé, Alexandre Desforges, Brigitte Vigolo

\section{- To cite this version:}

Mauricio Pavía, Khoder Alajami, Patrice Estellé, Alexandre Desforges, Brigitte Vigolo. A critical review on thermal conductivity enhancement of graphene-based nanofluids. Advances in Colloid and Interface Science, 2021, 294, pp.102452. 10.1016/j.cis.2021.102452 . hal-03250152

HAL Id: hal-03250152

https://hal-univ-rennes1.archives-ouvertes.fr/hal-03250152

Submitted on 4 Jun 2021

HAL is a multi-disciplinary open access archive for the deposit and dissemination of scientific research documents, whether they are published or not. The documents may come from teaching and research institutions in France or abroad, or from public or private research centers.
L'archive ouverte pluridisciplinaire HAL, est destinée au dépôt et à la diffusion de documents scientifiques de niveau recherche, publiés ou non, émanant des établissements d'enseignement et de recherche français ou étrangers, des laboratoires publics ou privés. 


\section{A critical review on thermal conductivity enhancement of graphene-based nanofluids}

Mauricio Pavía ${ }^{a}$, Khoder Alajami ${ }^{a}$, Patrice Estelléb, Alexandre Desforges ${ }^{a}$, Brigitte Vigolo ${ }^{a, *}$

${ }^{a}$ Université de Lorraine, CNRS, IJL, F-54000 Nancy, France

${ }^{\mathrm{b}}$ Univ. Rennes, LGCGM, F-35000 Rennes, France

Corresponding author: Brigitte Vigolo (Brigitte.Vigolo@univ-lorraine.fr)

\section{Highlights}

- To determine the key parameters to develop highly-efficient heat transfer fluids

- Preparation of graphene-based nanofluids with different types of graphene

- Effect of the used graphene and the preparation approach on the nanofluid thermal conductivity

- Quantitative comparison of the enhancement of thermal conductivity of the graphenebased nanofluids

\section{Keyworks}

Nanofluids; graphene; thermal conductivity; chemical modification;

performance comparison 


\begin{abstract}
Nanofluids which consist of nanoparticles added to conventional fluids (or base fluids) are considered as promising heat transfer fluids. Compared to metal, metal oxide nanoparticles and carbon nanotubes, graphene with its extremely high intrinsic thermal conductivity became the best candidate to design nanofluids. Such nanofluids have the potential to be highlyefficient heat transfer fluid by reducing loss of heat and increasing cooling rates. Over the last ten years, graphene-based nanofluids have shown significant thermal conductivity enhancements, however due to the numerous and interlinked parameters to consider, optimisation of their efficiency is still challenging. The present review article analyses and discusses the reported thermal conductivity in term of performance with respect to the amount of the used graphene to develop the prepared nanofluids. The enhancement of thermal conductivity must meet the minimal graphene amount due to its production cost and because graphene nanoparticles induces high viscosity in the nanofluid leading to higher energy consumption for the heat transfer systems. Unprecedented in the literature, this work proposes a simple approach to quantitatively compare the enhancement of the thermal conductivity of the nanofluids. The thermal conductivity performance parameter introduced could be applied to all nanofluid families and may become a reference tool in the nanofluid community. Such tool will help to determine the optimal preparation conditions without compromising the superior thermal performances.
\end{abstract}

\title{
Table of Contents
}

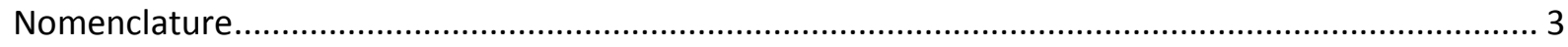

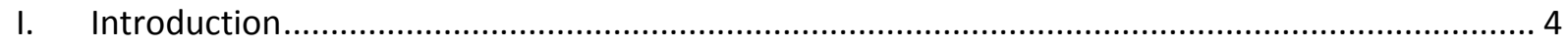

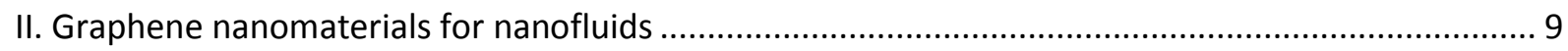

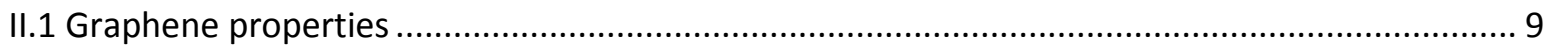

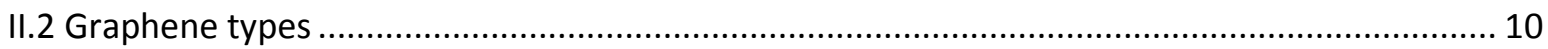


II.3 Graphene synthesis methods

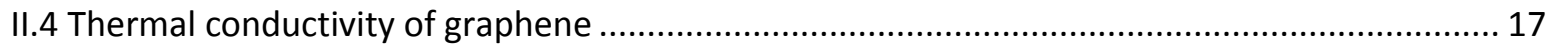

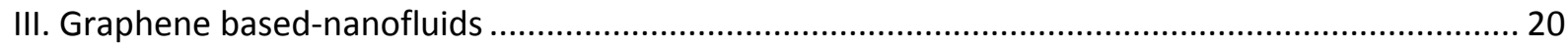

IV. Comparative analysis of thermal conductivity performances of graphene-based nanofluids ....... 23

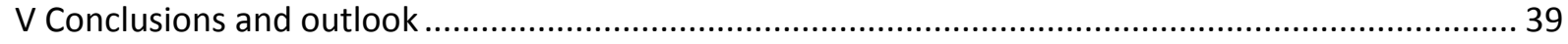

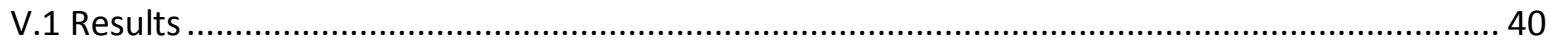

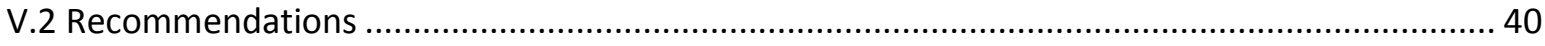

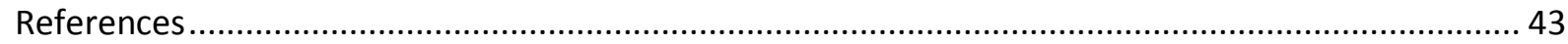

\section{Nomenclature}

$\begin{array}{ll}\text { GE } & \text { Graphene } \\ \text { NP } & \text { Nanoparticle } \\ \text { TC } & \text { Thermal Conductivity } \\ \text { DIW } & \text { Deionized Water } \\ \text { EG } & \text { Ethylene Glycol } \\ \text { Wt } \% & \text { Weight Percentage } \\ \text { SLG } & \text { Single Layer Graphene } \\ \text { GNS } & \text { Graphene Nanosheets } \\ \text { C/O } & \text { Carbon Oxygen ratio } \\ \text { DLG } & \text { Double Layered Graphene } \\ \text { TLG } & \text { Triple Layered Graphene } \\ \text { FLG } & \text { Few Layers Graphene } \\ \text { MLG } & \text { Multi Layered Graphene } \\ \text { GNF } & \text { Graphene based nanofluid } \\ \text { GNP } & \text { Graphene Nanoplatelets } \\ \text { GF } & \text { Graphene Flakes } \\ \text { GO } & \text { Graphene Oxide } \\ \text { rGO } & \text { Reduced Graphene Oxide } \\ \text { CVD } & \text { Chemical Vapor Deposition } \\ \text { HFGO } & \text { Highly Fluorinated GO } \\ \text { HRG } & \text { Highly Reduced Graphene Oxide } \\ \text { PVP } & \text { Polyvinyl Pyrrolidine } \\ \text { PG } & \text { Propylene Glycol } \\ \text { SDBS } & \text { Sodium Dodecyl Benzene Sulfonate } \\ \text { DOC } & \text { sodium deoxycholate } \\ \text { TPS } & \text { Transient Plate Source } \\ \text { THW } & \text { Transient Hot Wire } \\ \text { PEG } & \text { Polyethylene Glycol } \\ \text { TPS } & \text { Transient Plate Source } \\ \text { KPS } & \text { Potassium persulfate } \\ \text { LPE } & \text { Average Absolute Deviation (\%) } \\ \text { AAD } & \text { Gallic Acid } \\ \text { GA } & \text { Nriethanolamine } \\ \text { TEA } & \\ \text { NMP } & \end{array}$




$\begin{array}{ll}\text { NDG } & \text { Nitrogen Doped Graphene } \\ \text { HFGO } & \text { Highly Fluorinated Graphene Oxide } \\ \text { SAS } & \text { sodium 4-aminoazobenzene-4-sulfonate } \\ \text { SDS } & \text { Sodium Dodecyl Sulfate } \\ \text { GA } & \text { Gallic Acid } \\ \mathrm{T} & \text { Temperature } \\ \text { meas. } & \text { Measurements } \\ \text { conc. } & \text { Concentration } \\ \mathrm{TCe}_{30} & \text { Thermal conductivity enhancement value in } \% \text { at } 30^{\circ} \mathrm{C} \\ \mathrm{TC}_{\mathrm{nf}}\left(30^{\circ} \mathrm{C}\right) & \text { Thermal conductivity of the nanofluid at } 30^{\circ} \mathrm{C} \\ \mathrm{TC}_{\mathrm{bf}}\left(30^{\circ} \mathrm{C}\right) & \text { Thermal conductivity of the base fluid at } 30^{\circ} \mathrm{C} \\ \mathcal{P}_{\mathcal{T C}} & \text { TCe } \\ C_{G F} & \text { prepare the corresponding nanofluid. } \\ & \text { Concentration (in wt. } \%) \text { of the employed GE to prepare the nanofluid }\end{array}$

\section{Introduction}

Nanofluids, which consist of nanoparticles (NPs) added to conventional fluids (base fluids), have been considered as promising heat transfer fluids since their discovery by Choi and Eastman in 1995[1]. Many studies have shown the superior heat transfer properties of nanofluids, especially their thermal conductivity (TC) [2-9]. The role the nanofluids can play in thermal management is now widely recognized. The main idea is to disperse NPs possessing high thermal intrinsic conductivity in a solvent (or base fluid) in order to enhance the overall TC of the nanofluid. Therefore, the TC enhancement of the nanofluid is evaluated by taking the based fluid (with or without surfactant) TC as reference.

The nanofluids are envisaged to be used in cooling systems, for electronics or industrial engines requiring high thermal dissipation. And, efficiency of renewable energy like solar based on heat recovery and maximization of thermal transfer for storage or conversion would be boosted with the use of nanofluids[10,11].

Two main NP families have been investigated for nanofluids: metal based NPs (metals, oxides) and carbon nanomaterials (nanographite, nanodiamonds, carbon nanotubes and 
graphenic species). The properties of the NPs commonly used for nanofluid preparation are given in Table 1. This Table shows that both thermal and electrical conductivities of some nanoparticle species can be really high compared to usual heat transfer fluids, evidencing the interest of nanofluids.

Table 1 Physical properties of the commonly used nanoparticles and base fluids to prepare nanofluids.

\begin{tabular}{|c|c|c|c|}
\hline Nanoparticle & $\begin{array}{c}\text { Density } \\
\text { Kg.m }\end{array}$ & $\begin{array}{c}\text { Electrical } \\
\text { conductivity } \\
\left({\left.\mathrm{S} . \mathrm{m}^{-1}\right)}^{-3}\right.\end{array}$ & $\begin{array}{c}\text { Thermal } \\
\text { conductivity } \\
\left(\mathrm{W} . \mathrm{m}^{-1} . \mathrm{K}^{-1}\right)\end{array}$ \\
\hline $\mathrm{Cu}$ & $8933[12]$ & $5.96 \times 10^{7}[12]$ & $400[12]$ \\
\hline $\mathrm{Co}$ & $8900[12]$ & $1.60 \times 10^{7}[12]$ & $100[12]$ \\
\hline $\mathrm{CuO}$ & $6310[13]$ & $10^{-3}[14]$ & $33[15]$ \\
\hline $\mathrm{TiO}_{2}$ & $3900[16]$ & $10^{-1}[17]$ & $5.6[18]$ \\
\hline $\mathrm{Al}_{2} \mathrm{O}_{3}$ & $3500-3900[16]$ & $10^{-10}[19]$ & $6.9[20]$ \\
\hline $\mathrm{Fe}_{2} \mathrm{O}_{3}$ & $5180[12]$ & $0.112 \times 10^{6}[12]$ & $80.4[12]$ \\
\hline Carbon nanotubes & $\sim 700-1700[21]$ & $10^{6}-10^{7}[21]$ & $\sim 3000[22]$ \\
\hline $\mathrm{Graphene}$ & $20-2000[23]$ & $\sim 6 \times 10^{8}[23]$ & $\sim 5000[23]$ \\
\hline $\mathrm{GO}$ & $10-1910[24]$ & $5.7 \times 10^{-6}[23]$ & $0.5-18[23]$ \\
\hline $\mathrm{rGO}$ & $10-1910[24]$ & $10^{2}-10^{5}[23]$ & $1390-2275[23]$ \\
\hline water & 1000 & $5.5 \times 10^{-6}[25]$ & $0.596\left(20^{\circ} \mathrm{C}\right)[26]$ \\
\hline ethylene glycol & 1110 & $107[25]$ & $0.257\left(20^{\circ} \mathrm{C}\right)[27]$ \\
\hline
\end{tabular}

The intrinsic TC of the metal based NPs is in the $6-400 \mathrm{Wm}^{-1} \mathrm{~K}^{-1}$ range which is of two/three orders of magnitude higher than the commonly used base fluids, [10] e.g. deionized water (DIW), ethylene glycol (EG) or mixtures of both of them. For example, Aberoumand et al. experimentally studied the $\mathrm{TC}$ of $\mathrm{CuO}$ nanoparticles (mean diameter $1 \mathrm{~nm}$ ) in motor oil to investigate the effect of concentration and temperature on the TC of the nanofluids [28]. The concentrations of NPs in the base fluid were $0.2,0.5$ and $1 \%$ by weight. An enhancement of $49 \%$ in $\mathrm{TC}$ at $30{ }^{\circ} \mathrm{C}$ was found for 1 weight percentage (wt.\%) of CuO. Fedele et al. studied the effects of adding titanium oxide nanoparticles, $\mathrm{TiO}_{2}$ in water [29]. The results indicated that with 35 wt. $\%$ of $\mathrm{TiO}_{2}$, the nanofluid TC was increased by $23 \%$ at $30{ }^{\circ} \mathrm{C}$ compared to DIW alone. Other factors like the nanoparticles size can affect the TC of nanofluids. Sharifpur 
et al. have investigated the effect caused by the addition of $\mathrm{Al}_{2} \mathrm{O}_{3}$ of different sizes $(31 \mathrm{~nm}, 55$ $\mathrm{nm}$ and $134 \mathrm{~nm}$ ) to glycerol between 20 and $45^{\circ} \mathrm{C}$ [30]. The results showed that the maximum of improvement $\left(19.5 \%\right.$ in relative $\mathrm{TC}$ at $\left.30{ }^{\circ} \mathrm{C}\right)$ was reached for the smallest particles (31 $\mathrm{nm})$ for the same NPs concentration (4 vol.\%).

Other than metal or metal oxide NPs, carbon nanomaterials such as carbon nanotubes and graphene (GE), which combines lightness, chemical stability, high surface area, excellent mechanical properties and exceptional electrical and thermal properties, became a candidate of great interest to design high thermally conductive nanofluids [31]. GE which consists of carbons arranged in a regular $\mathrm{sp}^{2}$ bonded atomic-scale honeycomb pattern possess a remarkable intrinsic TC. In addition to TC enhancement of nanofluids their stability is another crucial challenge. Aggregation of carbon based-NPs is usually observed due to lack of affinity towards the base fluid. Attractive forces between them lead to sedimentation and finally nanofluid destabilization which hinders their scale-up transfer. In the case of GE, compared to metal-based NPs, its lightness is particularly favorable to prevent sedimentation effects. However, pristine defect-free GE is highly hydrophobic and has high tendency to form aggregates in aqueous solvents. To solve this problem, great efforts have been devoted to improve the dispersion stability of pristine GE by various approaches such as mechanical agitation, ultrasonic treatment and their chemical modification of GE surface with surfactants (non-covalent functionalization) or introduction of functional groups (covalent functionalization) [32-35]. These two approaches for GE surface modification have each their pros and cons. The covalent functionalization involves the introduction of high number of oxygen-containing functional groups that inevitably damage the GE network, which negatively affects its physical properties including the TC [36]. The non-covalent approach consists in adding surfactants that adsorbs onto the GE's external surface [37] forming a coating layer known to be responsible for limiting heat transfer within the GE nanofluid 
[38,39]. In both chemical approaches, significant TC enhancements mainly require high GE concentration which is prejudicial for developing low energy consumption systems due to the consequently increase in nanofluid viscosity [40-42]. More generally, because of the relatively high production cost of NPs, and GE is not an exception [43], the GE amount has to be minimized within nanofluids. The challenge for GE based nanofluids (GNFs) is indeed fully related to the ratio between $\mathrm{TC}$ enhancement and the amount of used GE to reach this enhancement.

Various sources of GE with different characteristics, available in large volumes from top-down methods $[44,45]$ are used for nanofluid preparation. Among the most used graphene derivatives, graphene nanoplatelets or graphene flakes have a poorly defected structure and graphene oxide (GO) [46] bears a lot of oxygen-containing groups. GO can be reduced to produce reduced GO (rGO) by following straightforward procedures [47]. Consequently, the structure of graphene is partly restored as well as its properties.

There is a variety of GE based materials and different methods can be used for their functionalization and their use for nanofluids preparation. In general, the TC of GNF nanofluids depends or increases with temperature and it is usually improved as the amount of GE is increased within the nanofluid (in the case of good conductive GE and without sedimentation). GNF have been the topic of several review papers these last years. Among them, the preparation methods used to produce these nanofluids and the involved stability issues have been widely discussed [32-34]. The TC enhancement is as well of utmost importance for the GNF topic. In 2016, two review papers analyzed the thermal properties of GNFs [48,49]. Indeed, Rasheed et al. investigated the factors affecting TC and tribological properties of GNF such as the nanoparticles concentration, the temperature and the graphene size [48]. Besides, in the review by Sadeghinezhad et al. [49], different applications related to thermal properties of GNF have been analyzed by discussing the numerous parameters that 
could affect the thermal efficiency. However, it remains difficult to directly compare the TC enhancement of the different nanofluids prepared. And despite the large number of GNF studies, the lack of understanding of the precise mechanisms and the relevant parameters affecting the GNFs properties has been pointed out. Identifying the optimum set of features that they must possess to maximize their properties is an open question. From there, any selection of the best GE type or the most promising functionalization approach cannot be done. Moreover, high presence of GE will increase the nanofluid viscosity triggering a higher energy consumption for heat transfer systems because higher pumping power is necessary $[50,51]$. This is the reason why minimizing GE concentration for nanofluid development is crucial [43]. In the present review, we propose a new and rigourous approach in order to provide a useful performance scale for GE based nanofluids. For that purpose, a performance parameter of GNF TC has been introduced. This new approach in the field could be applied to any other nanofluid type. Such performance parameter is of great usefulness for the nanofluid community and industry because such knowledge might become the basis to optimize GNF development and prepare high-performance GNF combining high stability and superior TC/GE amount ratio.

The present review is organized in three main parts. The first part gives a broad knowledge on the different types of GE nanomaterials used for nanofluid preparation, a focus is made on GE TC and the main methods for nanofluid preparation are briefly described. In the second part, an in-depth analysis of the TC performances is proposed. Finally, the third part will discuss the findings of the critical analysis and will give some recommendations for future works and development in GE nanofluids. 


\section{Graphene nanomaterials for nanofluids}

\section{II.1 Graphene properties}

GE is known for being a nanomaterial holding outstanding thermal and electrical properties. Nowadays, GE possesses a wide domain of applications, from the aerospace industry to the microelectronics and the energy management sector. GE also serves as elemental base of diverse carbon allotropes, for example by folding 2D GE sheets in cylinders is possible to form 1D carbon nanotubes. Furthermore, graphite is obtained when several GE sheets are stacked together. The GE history can be tracked back as far as 1859 when Brodi et al. did the first attempt to synthetize it [52]. Nevertheless, GE's breakthrough really started in 2004 when Novoselov et al. succeeded to synthetize an isolated GE sheet [53].

GE's atomic lattice follows a honeycomb pattern with the thickness of a single carbon atom. Carbon atoms are bonded to three other carbon atoms by a strong double covalent bond while each atom in the lattice suffers from a $\mathrm{sp}^{2}$ hybridization $[54,55]$. This hybridization is the origin of all GE's outstanding properties since the arrangement forms a perpendicular orbital to the sheet plane, inducing the behavior of a semiconductor or semimetal in the GE. The no existence of a band gap and the no overlapping of the GE's $\pi$ bands (valence bands) and $\pi^{*}$ bands (conduction bands) is another consequence of this feature [56,57]. Therefore, GE possesses the highest mobility of charge carriers among all known materials, with a value that reaches $200,000 \mathrm{~cm}^{2} \mathrm{~V}^{-1} \mathrm{~S}^{-1}[53]$.

In addition to remarkable electronical properties of GE, it also possess the highest TC ever reported in literature, with values of $5000 \mathrm{Wm}^{-1} \mathrm{~K}^{-1}$ at room temperature $[23,58,59]$. The previously mentioned properties explain the growing interest of researchers in exploiting GE in composites as reinforce material. 


\section{II.2 Graphene types}

Nowadays, the word "graphene" designs a wide group of GE derivative materials existing in the literature. Since their discovery, the demonstrated difficulty and cost of synthetizing a perfect single layer of graphene (SLG) or graphene nanosheet (GNS) has given rise to the existence of diverse GE derivative materials. The main difference between them is a variation on the number of layers, the lateral size and the presence of different functional groups on the GE surface.

The presence of defects is common in the GE derivative materials. These defects are introduced during the synthesis method because of the commonly harsh preparation conditions. Their existence is then difficult to avoid. However, these functional groups are also an important parameter to manage in such modified GE properties. The amount of functional groups attached on the GE surface can be defined by the carbon/oxygen ratio $(\mathrm{C} / \mathrm{O})$. This value impacts certain properties of GE. In other words, the diverse GE derivatives prepared possess different physical and chemical properties.

In the past years, a great effort has been made to homogenize the names given to the GE derivative materials [60]. Therefore, before performing a detail review of the GE based nanofluids, we first describe the most important graphenic derivative materials used for this purpose. The Figure 1 below represents the structural differences between some of the main existing GE derivatives. The axes represent the number of layers, the $\mathrm{C} / \mathrm{O}$ ratio content and the GE average lateral size respectively. 


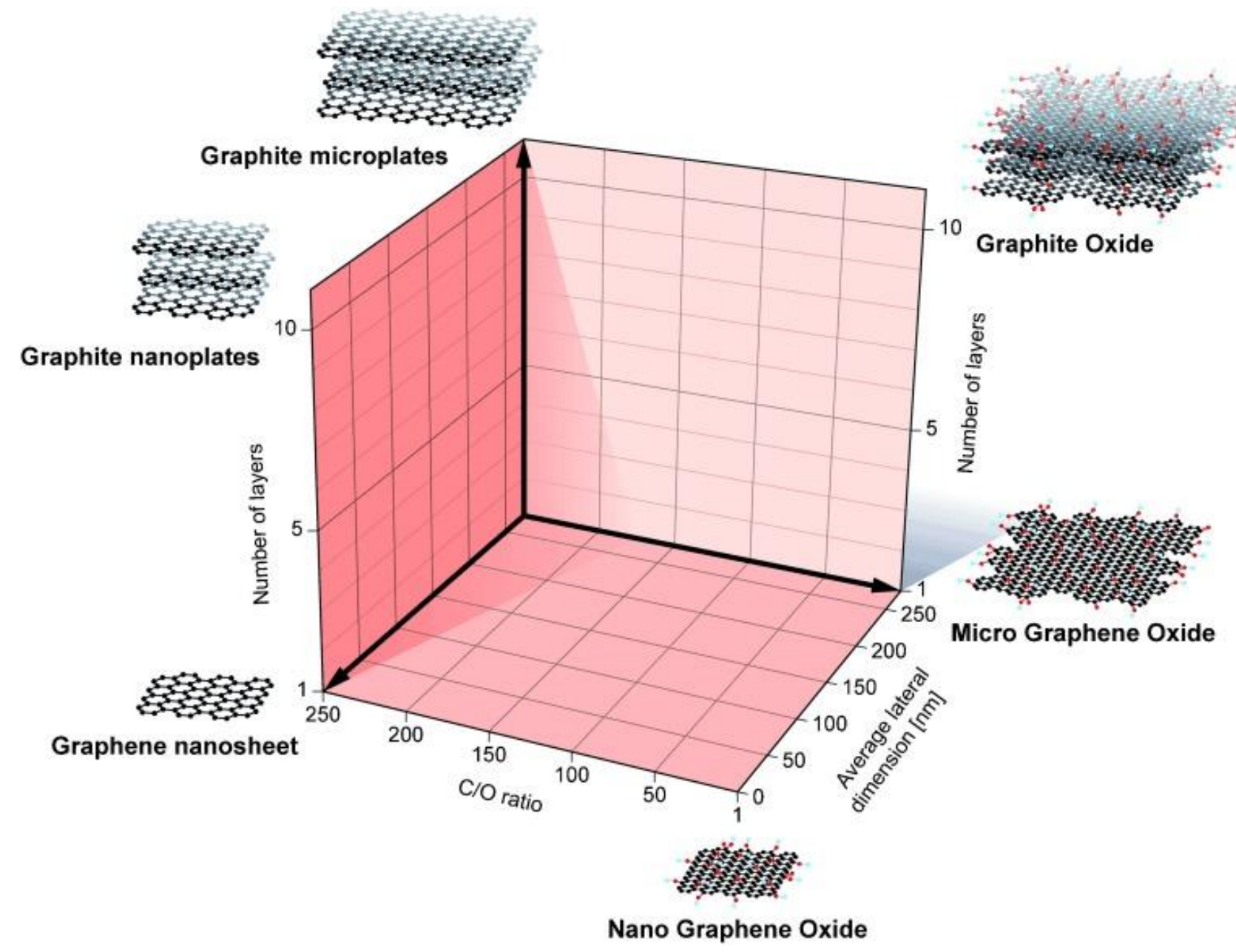

Figure 1 Possible GE derivatives classification following the number of layers, average lateral dimension and carbon/oxygen $(\mathrm{C} / \mathrm{O})$ ratio located in the three different axes properly. Reproduced with permission from Wick et al. [61]

- The double layered (DLG) and triple layered graphene (TLG) refer to materials formed by two and three GE sheets, respectively. Both are included in a more general category called few-layer graphene (FLG). In fact, a FLG is defined as a 2D carbon material containing between 2 and 5 well-defined and stacked GE layers. FLG presents a high specific surface, hydrophobicity and excellent thermal and electric properties. Beyond 5 and until 10 stacked GE sheets, the material is called multi-layered graphene (MLG). The previously described GE derivatives lay over the marked "graphene nanosheet" presented in Figure 1. 
- The graphene nanoplatelets or graphene flakes (GFs) are the graphenic derivative materials that, as it can be observed in Figure 1, contain more than 10 and until $30 \mathrm{GE}$ honeycomb lattice sheets. These graphene nanoplatelets present a high hydrophobicity, which hinders their water dispersion. Even though their elevated number of GE layers, this material is still considered as a nanomaterial since the thickness is around $0.335 \mathrm{~nm}$. For its remarkable electrical properties, GNPs are mainly used in electric applications like supercapacitors [62].

- The graphene oxide, well known as GO, originates from synthesizing a graphene derivative by an easy and cost-effective method. GO is mainly synthetized by oxidation and exfoliation hence this material is a chemical modified GE with a great content of oxygen type carboxylic $(\mathrm{COOH})$, alcohol $(-\mathrm{OH})$ and ether $(-\mathrm{COC})$ functional groups attached on the basal plane. The presence of the oxygenated groups on GE surface makes the GO water soluble [63]. However, the existing functional groups disrupt the $\mathrm{sp}^{2}$ hybridization bonding, distressing and lessening the GO thermal, mechanical and electrical properties. As shown in Figure 1, the nano GE oxide is characterized by a C/O ratio below 50 and a small lateral dimension.

- Later, reduced graphene oxide (rGO) was developed to improve the existing GO properties. Also, rGO is a particular GO that has been chemically treated to restore some of the damages caused by the oxidation in the $\mathrm{sp}^{2}$ bonds while conserving GO water solubility [47]. The $\mathrm{G} / \mathrm{O}$ ratio of the $\mathrm{rGO}$ is higher than that of $\mathrm{GO}$, thus even if it is not represented, the rGO would be located further left than the GO in Figure 1. GO and rGO low production cost and high scalability make possible to be applicable in conductive inks, battery electrodes, sensors, polymer fillers [64]. 
Additionally to the previously mentioned GE derivatives, some carbon derivatives such as the GE quantum dots (GQD) are also available, GQD being a material showing quantum confinement and edge effects [65].

\section{II.3 Graphene synthesis methods}

It is clear that the different GE derivatives would be produced from different synthesis methods. In this case and as in all nanomaterials, the synthesis methods can be classified following two main approaches: bottom up and top down. The bottom-up approach consists of synthetizing the material from its very low parts (atom by atom) until the assemblage of the whole while the top-down approach involves the reduction, exfoliation or milling of a macroscopic material until the production of the nanomaterial.

Figure 2 summarizes both approaches as well as the most common techniques used to synthesize GE. 


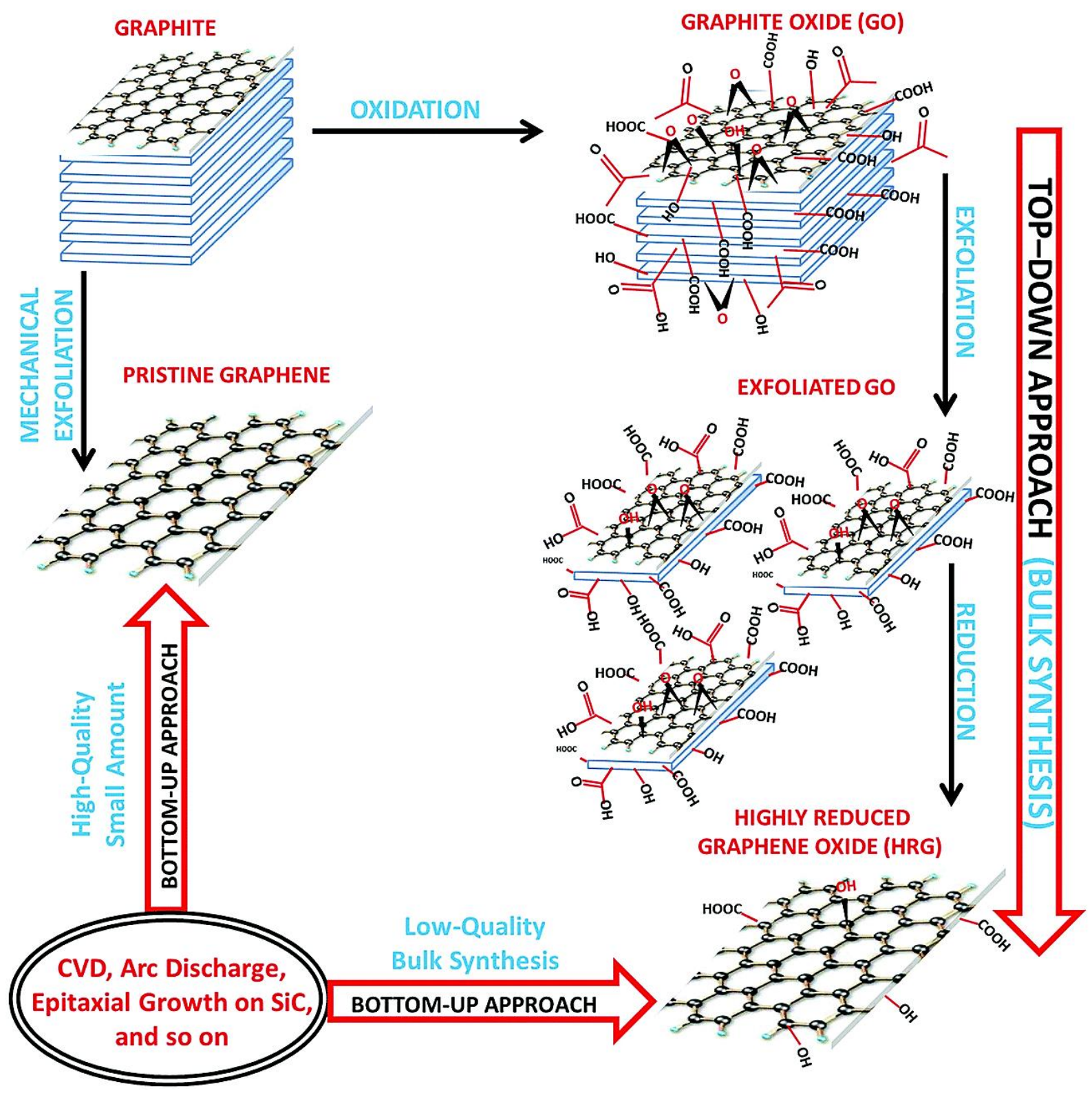

Figure 2 Schematic representation of the top-down and bottom-up approaches.

Reproduced with permission from ref. [66]

The Chemical Vapor Deposition (CVD) is the most representative process of the bottom-up approach. The CVD method is well recognized for allowing the successful production of pristine GE with a relatively well controlled number of layers (typically FLG, MLG and GNP) of several $\mathrm{cm}^{2}$ wafer-scale on metallic nickel, copper or even cobalt substrates serving as GE growth catalysts [67]. The process consists in injecting a gaseous 
mixture of a carbonaceous precursor often methane $\left(\mathrm{CH}_{4}\right)$, with hydrogen $(\mathrm{H})$ into a furnace heated up to $800^{\circ} \mathrm{C}$. The $\mathrm{CH}_{4}$ molecules dissociate at the heated metal surface, then they recombine and segregate into GE sheets. GE synthetized by this method is of high quality and is particularly used for research and development in electronics. Otherwise, the main drawbacks are the high amount of metallic and carbonaceous impurities present in the outcome material [68].

The solvothermal synthesis, a less known method of the bottom-up approach, involves the synthesis of GE by a reaction between an alcohol, which is the carbonaceous precursor, and an alkali metal, mostly sodium. Alcohol and sodium are mixed under an inert atmosphere and placed in a reactor at $200^{\circ} \mathrm{C}$. The obtained product is then pyrolyzed (i.e. heated to temperatures around $800^{\circ} \mathrm{C}$ inside an inert atmosphere). The resulting powder is then washed with hydrochloric acid to remove the impurities [69]. Following this washing, graphene in form of GO, FLG and MLG are obtained. Nevertheless, the final product yield is poor and the material suffers from a great amount of defects and impurities, mostly due the presence of sodium oxide $\left(\mathrm{Na}_{2} \mathrm{O}\right)$.

Historically, graphite exfoliation is the first acknowledged technique to produce GE and it is an example of a top-down synthesis method. Besides, the exfoliation can be done either mechanically or chemically. In Figure 2, it is possible to distinguish both methods; in this case, the chemical exfoliation is denoted as "exfoliation" while mechanical exfoliation is denoted "mechanical exfoliation".

GE synthesis method from mechanical exfoliation is based on the application of transverse or longitudinal stress on the graphite surface in order to prevail the van der Waals binding energy. Many agents can be used as stress appliers such as scotch tape [53] and electric field [70] making the mechanical exfoliation an efficient synthesize method. The 
relevance of this method is due to the high quality of the obtained "pristine GE derivatives". The GE derivatives are mostly FLG and GNF. However, the production yield is poor, making this technique not suitable for large-scale production. Nonetheless, a novel approach associated with the use of ultrasonication of GE in liquids has achieved a high production yield with low defects in the produced FLG [71,72] .

In the case of chemical exfoliation, harsh conditions are used to overcome the attractive van der Walls forces between the graphite layers. The solvents are either toxic organic solvents such as cyclohexanone (CYN), dimethyl sulfoxide (DMSO) or water. Use of water is particularly difficult since pristine GE is highly hydrophobic. Consequently, exfoliation in water is achieved with the help of surfactants that facilitate the exfoliation of graphite and stabilize (pre-disperse) the GE $[73,74]$. For instance Bourlinos et al. used pyridine as well as some non-aromatic solvents like ethyl acetate, vinyl acetate, methyl chloroacetate, among others to extract GE from graphitic powder, obtaining dispersed graphite at variable concentrations and different yields according to the employed surfactant [75]. The predilected synthetized product of the chemical exfoliation is the exfoliated GO as it is indicated in Figure 2.

The first chemical exfoliation method was performed by Brodi et al. [52]. This method involved the use of strong acids such as nitric acid $\left(\mathrm{HNO}_{3}\right)$, representing a high risk and danger compared to the low production yield [52]. Years later, Staudenmaier et al. and Hofmann et al. improved Brodi's method achieving an increase in the produced GO yield [7678]. Nevertheless, the production method was still being dangerous by the utilization of strong acids. Afterwards, Hummers et al. developed a chemical exfoliation procedure that currently is the most common method to synthetize chemically exfoliated GE [46]. This approach employs strong oxidants such as potassium permanganate $\left(\mathrm{KMnO}_{4}\right)$, hydrogen peroxide $\left(\mathrm{H}_{2} \mathrm{O}_{2}\right)$ and concentrated sulfuric acid $\left(\mathrm{H}_{2} \mathrm{SO}_{4}\right)$. The compounds oxidize the GE planes and 
this oxidation reaction causes the distance between the GE sheets to increase. Both washing and decantation cycles must be carried out in order to return to a neutral $\mathrm{pH}$, then the resulting GO should be dried. Hummers' method allows the production of GO in relatively large quantities with a limited presence of defects. In the recent years, modifications of this procedure have been reported in the literature, known as the "modified Hummers' methods" $[79,80]$.

The rGO can be obtained by chemical reduction of GO [81,82]. This reduction can be simply achieved by adding different reducers to a dispersion of GO in water such as ascorbic acid, hydrazine and sodium borohydride. The final product, the highly rGO (HGR), most commonly denoted as rGO, possesses a small amount of oxygenated groups as it is evidenced in Figure 2. The fact that oxygenated groups are chemically reduced induces a partial restoration of the $\mathrm{sp}^{2}$ network [83]. The reduction of these groups brings an increase in the thermal and electrical conductivity of rGO with respect to GO $[81,82,84,85]$. GO is an electrical insulator with a conductivity less than $10 \mu \mathrm{S} / \mathrm{m}$ (Table 1). Graphene conductivity depends indeed on the extend of oxygen groups [86]. By reducing them by a chemical or thermal method, an increase in electrical conductivity was then observed in the 1-2000 S/cm range depending on the structural quality of the studied $\mathrm{rGO}[85,87,88]$. Moreover, an increase of thermal conductivity of composites and films when GO was reduced to rGO was widely reported [87,89-92]. Such an enhancement is attributed to the increase in thermal conductivity of rGO compared to that of GO as evidenced in Table 1.

\section{II.4 Thermal conductivity of graphene}


Even if the TC measurement depends on the type of the investigated method (theoretical or experimental), the reported values for GE being in the $2000-10000 \mathrm{Wm}^{-1} \mathrm{~K}^{-1}$ are remarkably high $[58,59,93]$. These studies are mainly focused on CVD synthetized GE. Topological defects are often introduced in the outcome material since during the $\mathrm{CH}_{4}$ dissociation process the GE structure can suffer from regional overlapping and rupture [94]. Additionally, most of research on TC has been carried out in suspended CVD grown GE. Experimentally, TC is usually measured by the optothermal Raman technique but the presence of a substrate leads to uncontrolled effects due to phonon leakage across the GEsubstrate interface [95]. TC of GE may be affected by several factors including the lateral dimensions of the layer, the edge states, the number of layers and the number of defects [9699]. The majority of studies, either experimental or theoretical, have reported that TC is reduced by increasing defect density within the GE structure by functionalization $[82,100$ 103] or doping [36] (Figure 3). It was also claimed that depending on the functionalization level in the case of grafting of nitrophenyl groups covalently bonded to GE, TC could be even increased [104]. The intrinsic TC of GNP, GF, GO or rGO has been poorly investigated so far.

Chemical modifications of the GE are an alternative to improve its properties especially its high hydrophobicity. The chemical modification of GE surface can be done either from covalent or non-covalent approach. Both types of functionalization are commonly used, at an equivalent level, to design GNFs. In the following, the influence of these two different types of functionalization on GE TC is evaluated.

Concerning the covalent functionalization, the introduction of defects at the functionalized carbon site unavoidably modifies the $\mathrm{sp}^{2}$ hybridization leading towards a $\mathrm{sp}^{3}$ hybridization since the $\mathrm{C}=\mathrm{C}$ double bonds must be "broken" to serve as attachment sites for the foreign molecules. The additional phonon scattering due to the defected network reduces the TC of the modified GE, as illustrated in Figure 3. 


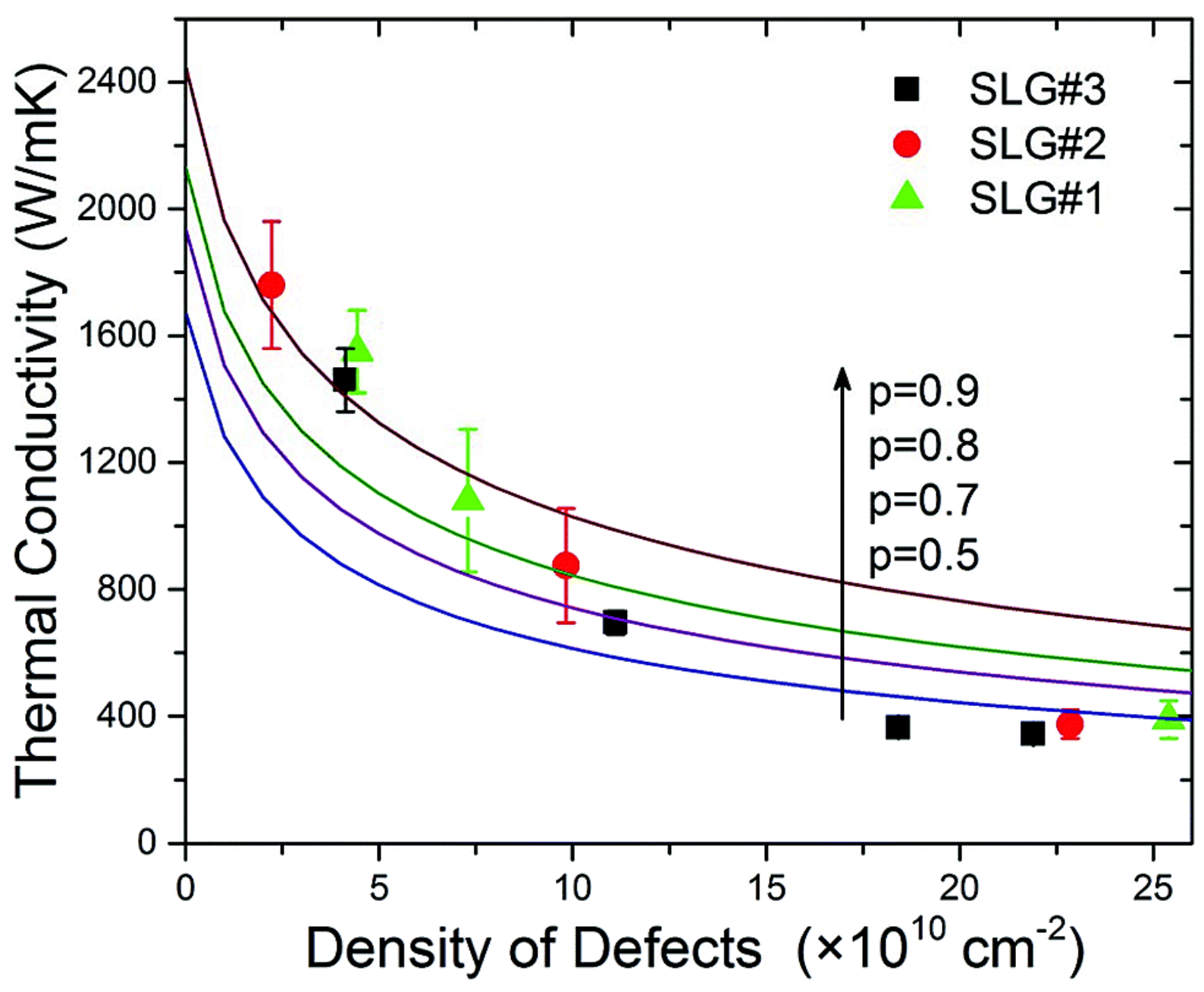

Figure 3 Dependence of the TC on the density of defects of SLG. The experimental data are shown by squares, circles and triangles. The solid curves are calculated curves. $p$ is a parameter called the specularity parameter; for $p=0$ the scattering is fully diffuse and for $p=1$, there is no extra thermal resistance due to diffusion. Reproduced with permission from ref. [36]

Regarding the non-covalent approach, for which the $\mathrm{sp}^{2}$ network remains intact, negative effects on the TC due to addition of surfactants have been reported [38,39]. The surfactants are usually organic compounds having intrinsic low TC. Even if low concentration are usually used, their presence in the base fluid is known to diminish the TC of the solventsurfactant mixtures compared to the solvent alone [105]. Moreover, it has been already 
reported that the surfactant molecules on the GE surface acts as an insulating layer, limiting the transfer between the dispersed GE and consequently decreasing the thermal and electrical conductivity of the resulting nanofluid $[39,106]$. Yu et al. reported that $5 \mathrm{wt} \%$ of polyvinyl pyrrolidone (PVP) used as surfactant decreased the TC of EG-PVP mixture by about $2 \%$ compared to that of pure EG [107]. In another work, an ionic surfactant, sodium dodecylbenzene sulfonate (SDBS), used at a concentration of 1 vol.\% reduced the TC of $\mathrm{Al}_{2} \mathrm{O}_{3}$-based nanofluids. This effect has been shown to be even worse by increasing the $\mathrm{SDBS} / \mathrm{Al}_{2} \mathrm{O}_{3}$ volumetric ratio [108].

\section{Graphene based-nanofluids}

Generally, nanofluids can be prepared by either a one- or two-stage approach. Mostly DIW, EG, propylene glycol (PG), ionic liquids and oils, like kerosene, are used as a base fluid. Also, a mixture of the previously mentioned solvents can be use as based fluids. The one-step method for preparing nanofluids is less used than the two-steps approach. It involves the synthesis of the NPs and their simultaneous dispersion in the base fluid using different chemical or physical methods such as physical/chemical vapor deposition or laser ablation. For example, Akoh et al. developed a one-step synthesis method via evaporation/condensation [109]. A metal vapor is directly condensed into nanoparticles when it comes into contact with a low vapor pressure fluid, in this case EG. The resulting nanofluid is formed by metallic nanoparticles with an average diameter of $2.5 \mathrm{~nm}$, suspended in the EG solution . Laser ablation is a recent technique that has proven its effectiveness. An example is the work of Mortazavi et al., whom achieved the synthesis of a graphene material with thickness of $0.07 \mathrm{~nm}$ inside an liquid nitrogen atmosphere [110].

The one-step technique has the advantage of improving the stability with less NP agglomeration in the resulting GE-based nanofluid. Although, its two main disadvantages are 
the presence of residual reactants in the outcome solution due quite often incomplete chemical reaction and the elevated production cost that makes it unsuitable for large-scale production. Besides, due to its complexity, the one-step approach is rarely used to produce GNF nanofluids.

Unlike the one-step method, the two-step method is more suitable for high-scale production. Moreover, this is the most economical and widely used method for preparing nanofluids, including GNFs. Here, the nanoparticles are first synthesized in powder form, followed or not by chemical treatments (covalent functionalization). Then, the desired amount of solid is added to the host fluid (DIW, EG, etc.). Additives such as surfactants can be added to the solution to improve the nanoparticle dispersion by non-covalent functionalization. Most of the times, the solution must be agitated by ultrasonication to promote the solute dispersion of NPs, homogenization [32,111] and reduce GE aggregation.

A homogeneously well dispersed GE is essential to obtain long-term thermal properties of nanofluids [112]. Stability is recognized as a long-standing problem. Nanofluid destabilization limits the development and use of GNFs. The commonly observed weak dispersion stability of GE in the base fluid is a direct consequence of its high hydrophobicity and its resulting tendency to form aggregates.

For a better understanding of the nanofluids stability, it is important to know the factors that affect the NP dispersion. The dispersion stability depends on the interactions of various microscopic forces that are exerted on the NPs. Truth is that differences in the solution density causes the gravity forces to inevitable sediment the dispersions. Meanwhile, NPs in the fluid undergo a random thermal movement, the "Brownian motion" which is defined as an irregular and random motion of a large particle immersed in a fluid and which is subject to shock interactions with the small molecules of the fluid [113]. If the repulsive forces 
between these molecules or NPs is not strong enough, attractive (often van der Waals) interactions will induce their aggregation and nanofluid destabilization.

It is important to mention that, in recent years, a great effort has been devoted to overcome this problem. Chemical modifications of carbon nanomaterials and especially GE via non-covalent or covalent functionalization is commonly used to overcome its high hydrophobicity and enhance its dispersion. The functionalization modifies GE surface and therefore, the carbonaceous materials would be able to counterbalance the van der Waals aggregation force.

The covalent functionalization involves grafting hydrophilic functions on the GE sheets, mainly oxygenated functions, by covalent bonds. The main reactants in this process are acids and strong solvents. The remaining hydrophilic molecules on GE later improves its dispersion in the base fluid by electrostatic and steric repulsions [114-116]. Furthermore, while the pristine GE is chemically inert and zero band gap material, functionalized GE can be used for a new generation of engineered devices and the functionalization could even be used to tune the material's properties. Indeed, using defected GNS leads to better interface interactions and transfer phenomena between GE and the surrounding medium inducing a series of enhancement in some of the mixture properties such as mechanical, electrical and thermal compared to the pure surrounding medium (polymer, solvent...).

The non-covalent functionalization uses surfactants, molecules with a hydrophilic and a hydrophobic part, to disperse the GE in the nanofluid. The surfactants help to counterbalance the aggregation force since their hydrophobic part adsorbs on the GE surface while the hydrophilic part is in contact with the solvent, increasing the affinity of GE nanolayers with the base fluid by steric repulsion. Depending on the surfactant polar group nature (ionic, nonionic, cationic) electrostatic repulsions can also be exerted between the functionalized GE sheets. The $\mathrm{pH}$ also influences the repulsion exertion forces between the 
surrounding fluid and the grafted compound [117]. The non-covalent functionalization is relatively simple to implement and allows to preserve the GE physical properties since it does not induce any damage on the $\mathrm{sp}^{2}$ network.

Among the many existing techniques reported in the literature to measure the nanofluids stability, Zeta potential measurements, UV-Vis spectrometer and sedimentation photograph capturing figure are among the most common. The first two techniques offer a quantitative and trustful analyze while the third one is merely qualitative. Concerning the TC, among the diverse existing techniques, the Transient Plate Source (TPS) and the Transient Hot Wire (THW) methods are mainly used, as shown later in Table 2, due to their reliability and accuracy.

\section{Comparative analysis of thermal conductivity performances of graphene-based nanofluids}

The literature concerning the thermal performance of GE-based nanofluids is extensive. Among the reported results, different sets of experimental conditions have given different results in TC enhancements. These experimental conditions are numerous: TC measurement device, temperature range investigated, GE amount, based fluid nature, GE type and chemical modification and presence of surface agents among others. Such complexity explains the difficulty to directly compare the reported TC enhancements found for different nanofluids. In this section, we propose a tool whose main goal is to serve as a performance indicator of TC enhancement.

For that purpose, this review proposes a rational comparison of the thermal conductivity of GNFs reported in the literature over the last 10-year of publications. This 
review excludes the hybrid nanofluids. Table 2 gathers information extracted from the works published on GNFs and their TC enhancements to date. More than 60 papers and studies have been analyzed. For each analyzed work, the type of GE (and its source) used for the nanofluid development and the concentration range investigated are given as well as the chemical modification possibly applied to optimize the nanofluid preparation. This includes pristine GE nanomaterials (without functionalization) and GE having undergone either covalent or noncovalent functionalization. Regarding the nanofluid preparation, the used method and the chosen base fluid are also given. For the TC measurements carried out, the used method and the temperature range investigated are also specified. This detailed description of the nanofluid preparation and studied parameters is useful to compare the GE based nanofluid or to reproduce the reported experiments. With the aim of proposing a simple approach to quantitatively compare the enhancement of the measured TC of the nanofluid compared to the TC of the base fluid (without GE), the best TC enhancement at the same temperature was extracted from each study. Therefore, $30^{\circ} \mathrm{C}$ was selected as it is the most representative temperature investigated. This TC enhancement value in $\%$ at $30^{\circ} \mathrm{C}$ is referred to as $\mathrm{TCe}_{30}(\%)$ and is defined by the equation (1).

$T C e_{30}(\%)=\frac{T C_{n f}\left(30^{\circ} \mathrm{C}\right)}{T C_{b f}\left(30^{\circ} \mathrm{C}\right)} \times 100$

Where, $T C_{n f}\left(30^{\circ} \mathrm{C}\right)$ and $T C_{b f}\left(30^{\circ} \mathrm{C}\right)$ are the $\mathrm{TC}$ of the nanofluid and the base fluid at $30^{\circ} \mathrm{C}$, respectively.

Beyond this TC enhancement value alone, it appears particularly relevant for nanofluid development to relate this enhancement to the amount of GE inducing the nanofluid TC increment. Interestingly, by simply dividing the $\mathrm{TCe}_{30}(\%)$ by the concentration of GE (wt.\%) used to prepare the corresponding nanofluid, we introduce a universal parameter useful to compare the performance between different nanofluids. This parameter, defined by equation 
(2), is a thermal conductivity performance parameter $\left(\mathcal{P}_{\tau C}\right)$ directly linked to the efficiency of the used GE to enhance the TC of the prepared nanofluid. Therefore, this parameter is defined by equation (2).

$P_{T C}=\frac{T C e_{30}(\%)}{C_{G E}(w t . \%)}$

where $C_{G E}$ is the concentration in (wt.\%) of the employed GE.

$\mathcal{P}_{\mathcal{T C}}$ corresponds to the TC enhancement induced by $1 \mathrm{~g}$ of the corresponding GE type dispersed in the base fluid for $100 \mathrm{~g}$ of GNFs. For example, if high GE concentration induces a high TC enhancement in the nanofluid, the $\mathcal{P}_{\mathcal{T C}}$ value could be even lower than for a nanofluid for which the TC enhancement is less but prepared with a much lower GE amount.

As previously mentioned, high GE concentration in nanofluids leads to an increase in their viscosity. This is the reason why using low GE concentration is crucial. Furthermore, apart from TC enhancement, viscosity and more generally rheological behavior of nanofluids (not studied here) is another important parameter to study for the designed GNFs [41]. The used GE amount is an important parameter to consider for evaluating the nanofluid TC performance. And an optimal GE amount has to be found for nanofluid designing since it can represent around $80 \%$ of the nanofluid production cost [43].

From the data gathered in Table 2, an analysis of the evolution of the GE nanofluid performances regarding their TC is proposed below. 
Table 2 Graphene-based nanofluid preparation conditions, including GE source, functionalization approach, base fluid, GE concentration range and dispersion method, and thermal conductivity at $30^{\circ} \mathrm{C}$ along with the measurement method, the temperature range and the reported thermal conductivity at $30^{\circ} \mathrm{C}, \mathrm{TCe}_{30}$ and the calculated nanofluid $\mathrm{TC}$ performance parameter $\mathcal{P}_{\mathcal{T} C^{\circ}}$

\begin{tabular}{|c|c|c|c|c|c|c|c|c|c|c|c|c|c|c|}
\hline \multirow{2}{*}{\multicolumn{2}{|c|}{ GE type }} & \multirow{2}{*}{\multicolumn{6}{|c|}{ Nanofluid preparation }} & \multicolumn{5}{|c|}{ NF thermal conductivity } & \multirow{2}{*}{\multicolumn{2}{|c|}{ Published work }} \\
\hline & & & & & & & & \multicolumn{2}{|l|}{ TC measurement } & \multicolumn{3}{|c|}{ TC performance } & & \\
\hline \multirow{2}{*}{ type } & \multirow{2}{*}{ source } & \multirow{2}{*}{$\begin{array}{l}\text { metho } \\
\quad d\end{array}$} & \multirow{2}{*}{ base fluid } & \multicolumn{2}{|c|}{ functionalization } & \multirow{2}{*}{$\begin{array}{l}\text { conc. } \\
\text { range } \\
\text { (wt.\%) }\end{array}$} & \multirow{2}{*}{ method } & \multirow{2}{*}{ method } & \multirow{2}{*}{$\begin{array}{l}\text { T range } \\
\left({ }^{\circ} \mathrm{C}\right)\end{array}$} & \multirow{2}{*}{$\begin{array}{l}\text { GE conc. } \\
\text { (wt.\%) }\end{array}$} & \multirow{2}{*}{$\begin{array}{c}\mathrm{TCe}_{30} \\
(\%)\end{array}$} & \multirow{2}{*}{$\begin{array}{c}\mathcal{P}_{\tau C} \\
\text { (\%/wt.\%) }\end{array}$} & \multirow{2}{*}{ date } & \multirow{2}{*}{ Ref. } \\
\hline & & & & covalent & $\begin{array}{c}\text { non- } \\
\text { covalent }\end{array}$ & & & & & & & & & \\
\hline GNP & commercial & 2-step & kerosene & NO & oleylamine & $\begin{array}{c}0.0005- \\
0.2\end{array}$ & $\begin{array}{c}\text { Ultrasonic probe, } 40 \mathrm{~min} \\
-3 \mathrm{~h}\end{array}$ & $\begin{array}{c}\text { THW (KD2 Pro) accuracy } \\
\pm 5 \%\end{array}$ & $20-70$ & 0.2 & 23 & 115 & 2016 & [118] \\
\hline GF & commercial & 2-step & DIW & NO & SDBS & $\begin{array}{c}0.093- \\
0.28 \\
\end{array}$ & Sonication $30 \mathrm{~min}$ & THW & $10-50$ & 0.28 & 35 & 126 & 2016 & [119] \\
\hline GNP & commercial & 2-step & DIW & PEG & NO & $0.01-0.1$ & $\begin{array}{l}\text { Ultrasonic bath } 200 \mathrm{~W} \\
\quad 60 \mathrm{kHz}, 2 \mathrm{~h}\end{array}$ & $\begin{array}{l}\text { THW (KD2 Pro Decagon } \\
\text { Devices, Washington,USA) } \\
\text { average of } 5 \text { meas. }\end{array}$ & $20-60$ & 0.1 & 11 & 110 & 2019 & [120] \\
\hline GO & $\begin{array}{l}\text { Hummers' } \\
\text { method }\end{array}$ & 2-step & EG & $\begin{array}{l}\mathrm{H}_{2} \mathrm{SO}_{4}: \mathrm{HNO} \\
{ }_{3} \text { oxidized }\end{array}$ & NO & & $\begin{array}{c}\text { Ultrasonication } 30 \mathrm{~Hz} \\
30-45 \mathrm{~min}\end{array}$ & $\begin{array}{l}\text { THW (KD2 Pro Decagon, } \\
\text { Canada) uncertainty < } 4 \%\end{array}$ & $25-50$ & 0.1036 & 18 & 174 & 2010 & [116] \\
\hline GO & $\begin{array}{l}\text { Hummers' } \\
\text { method }\end{array}$ & 2-step & DIW & $\begin{array}{c}\text { hydrogen } \\
\text { exfoliated + } \\
\mathrm{H}_{2} \mathrm{SO}_{4}: \mathrm{HNO} \\
{ }_{3} \text { oxidized }\end{array}$ & NO & $0.01-0.1$ & $\begin{array}{l}\text { Ultrasonication during } \\
\text { 30-45min }\end{array}$ & $\begin{array}{l}\text { THW (KD2 Pro Decagon, } \\
\text { Canada) }\end{array}$ & $25-50$ & 0.1 & 22 & 212 & 2011 & [115] \\
\hline GNP & commercial & 2-step & $\begin{array}{c}\mathrm{DIW}+\mathrm{EG} \\
(90: 10)\end{array}$ & $\begin{array}{l}\text { sulfonic } \\
\text { acid }\end{array}$ & NO & $0.1-0.5$ & $\begin{array}{l}\text { Ultrasonic bath 200W, } \\
\qquad 40 \mathrm{kHz}\end{array}$ & $\begin{array}{c}\text { TPS (Hot Disk AB, Sweden) } \\
\text { input time } 4 \mathrm{sec} \text {, accuracy } \\
5 \% .\end{array}$ & $20-70$ & 0.5 & 5 & 10 & 2017 & [121] \\
\hline GNP & commercial & 2-step & $\begin{array}{l}\text { Heavy } \\
\text { duty } \\
\text { diesel } \\
\text { engine oil } \\
\text { CH-4 } \\
20 \mathrm{~W}-50\end{array}$ & NO & $\begin{array}{c}\text { Lipophilic } \\
\text { polymer } \\
\text { WinSperse } \\
6020\end{array}$ & $0.5-3$ & $\begin{array}{l}\text { Magnetic Stirring and } \\
\text { ultrasonic bath }\end{array}$ & TPS (Hot Disk AB, Sweden) & $20-70$ & 3 & 23 & 7.7 & 2020 & [122] \\
\hline
\end{tabular}




\begin{tabular}{|c|c|c|c|c|c|c|c|c|c|c|c|c|c|c|}
\hline GNP & commercial & 2-step & $\begin{array}{l}\text { hydrogen } \\
\text { ated oil }\end{array}$ & NO & NO & $\begin{array}{c}0.0025- \\
0.01\end{array}$ & $\begin{array}{l}\text { Ultrasonic bath } 3 \mathrm{~h}, \\
320 \mathrm{~W}, 40 \mathrm{kHz}\end{array}$ & THW (KD2 Pro Decagon) & $30-50$ & 0.01 & 10 & 1000 & 2017 & [123] \\
\hline GO & commercial & 2-step & DIW & NO & NO & $0.001-0.5$ & Ultrasonication $5 \mathrm{~min}$ & $\begin{array}{c}\text { TPS (TPS2500, Hot Disk } \\
\text { Inc., Sweden) accuracy } \\
\pm 3 \%\end{array}$ & $30-80$ & 0.1 & 19 & 190 & 2017 & [124] \\
\hline $\mathrm{rGO}$ & commercial & 2-step & DIW & NO & PVP & N.A. & Ultrasonication $5 \mathrm{~min}$. & $\begin{array}{c}\text { TPS (TPS2500, Hot Disk } \\
\text { Inc., Sweden) accuracy } \\
\pm 3 \%\end{array}$ & $30-80$ & 0.02 & 9 & 450 & 2017 & [125] \\
\hline GO & $\begin{array}{l}\text { Hummers' } \\
\text { method }\end{array}$ & 2-step & DIW & NO & NO & $0.01-0.1$ & $\begin{array}{c}\text { Sonication } 130 \mathrm{~W}, 42 \\
\mathrm{kHz}, 1 \mathrm{~h}\end{array}$ & $\begin{array}{l}\text { THW (KD2 Pro Decagon } \\
\text { Devices, Inc., Pullman, WA, } \\
\text { USA) uncertainty } 5 \%\end{array}$ & $25-40$ & 0.1 & 22 & 220 & 2017 & [126] \\
\hline GNP & commercial & 2-step & $\begin{array}{c}\text { DIW + EG } \\
(1: 1)\end{array}$ & NO & NO & $\begin{array}{l}0.05- \\
0.15\end{array}$ & Ultrasonication $1 \mathrm{~h}$ & $\begin{array}{c}\text { THW (KD2 Pro Decagon } \\
\text { Devices, Inc.) accuracy } \\
\pm 3 \%\end{array}$ & $\begin{array}{l}(-20)- \\
50\end{array}$ & 0.15 & 16 & 107 & 2018 & [127] \\
\hline FLG & CVD & 2-step & DIW & $\begin{array}{l}\text { alkaline } \\
\text { oxidation } \\
\text { by KPS }\end{array}$ & NO & $0.05-0.1$ & 15 minutes sonication & $\begin{array}{c}\text { THW (KD2Pro Decagon } \\
\text { Devices, Inc.) accuracy } \\
\pm 0.001\end{array}$ & $10-60$ & 0.075 & 51 & 680 & 2014 & [128] \\
\hline FLG & CVD & 2-step & DIW & $\begin{array}{l}\text { alkaline } \\
\text { oxidation } \\
\text { by KPS }\end{array}$ & NO & $\begin{array}{c}0.01- \\
0.05\end{array}$ & Ultrasonic water, 1 hour & $\begin{array}{l}\text { THW (KD2 Pro device } \\
\text { Decagon Devices, Inc.) }\end{array}$ & $10-50$ & 0.05 & 15 & 300 & 2013 & [129] \\
\hline GQD & commercial & 2-step & DIW & NO & NO & $\begin{array}{c}0.0025- \\
0.02\end{array}$ & Ultrasonic Probe. & $\begin{array}{l}\text { THW (KD2 Pro device } \\
\text { Decagon Devices, Inc.) }\end{array}$ & $20-60$ & 0.02 & 9 & 450 & 2017 & [130] \\
\hline $\mathrm{rGO}$ & $\begin{array}{l}\text { Hummers' } \\
\text { method }\end{array}$ & 2-step & DIW & NO & NO & $\begin{array}{l}0.1- \\
0.37\end{array}$ & N.A. & $\begin{array}{l}\text { THW, error }<1.2 \% \text {, } \\
\text { average of } 8 \text { meas. }\end{array}$ & $25-65$ & 0.37 & 11 & 30 & 2011 & [131] \\
\hline GO & $\begin{array}{l}\text { Hummers' } \\
\text { method }\end{array}$ & 2-step & EG & NO & NO & $\begin{array}{c}0.001- \\
0.07\end{array}$ & $\begin{array}{l}\text { Probe ultrasonication } 50 \\
\text { W, } 15 \mathrm{~min}\end{array}$ & $\begin{array}{l}\text { THW (KD2 Pro Decagon } \\
\text { Devises, Inc.) }\end{array}$ & $20-70$ & 0.07 & 31 & 443 & 2014 & [132] \\
\hline GO & $\begin{array}{l}\text { Hummers' } \\
\text { method }\end{array}$ & 2-step & DIW & NO & NO & $\begin{array}{c}0.05- \\
0.25\end{array}$ & $\begin{array}{c}\text { Ultrasonic Bath with } 200 \\
\text { W at } 60 \mathrm{kHz}\end{array}$ & $\begin{array}{l}\text { THW, KD2 Pro (Decagon } \\
\text { devices, Inc., USA) } \\
\text { accuracy }<5 \%,\end{array}$ & $10-40$ & 0.25 & 45 & 180 & 2014 & [133] \\
\hline
\end{tabular}




\begin{tabular}{|c|c|c|c|c|c|c|c|c|c|c|c|c|c|c|}
\hline FLG & $\begin{array}{l}\text { LPE (Liquid } \\
\text { Phase } \\
\text { Exfoliation) }\end{array}$ & 2-step & $\begin{array}{l}\text { PG:DIW } \\
(40: 60)\end{array}$ & NO & $\begin{array}{l}\text { P-123 } \\
\text { Pluronic }\end{array}$ & $0.05-0.5$ & $\begin{array}{c}\text { Probe sonicatior, } 125 \mathrm{~W} \\
\text { pulse mode, } 2 \mathrm{~s} \text { ON and } 1 \\
\text { OFF }\end{array}$ & $\begin{array}{l}\text { THW (THW-L2 device, } \\
\text { Thermtest Inc., Richibucto } \\
\text { Road, NB, Canada), } \\
\text { average absolute deviation } \\
\text { (AAD) } 1 \% \text {, average of } 6 \\
\text { meas. }\end{array}$ & $10-50$ & 0.5 & 27 & 54 & 2020 & [74] \\
\hline GO & $\begin{array}{l}\text { Hummers' } \\
\text { method }\end{array}$ & 2-step & $\begin{array}{l}\text { DIW:EG } \\
(60: 40)\end{array}$ & NO & NO & $\begin{array}{l}0.01- \\
0.10\end{array}$ & $\begin{array}{c}\text { Sonication bath, } 40 \mathrm{kHz} \text {, } \\
280 \mathrm{~W} \text { and stirring } 10 \\
\text { min }\end{array}$ & $\begin{array}{l}\text { THW (KD2 Pro Decagon } \\
\text { device) accuracy } \pm 5, \\
\text { average of } 6 \text { meas. }\end{array}$ & $25-45$ & 0.1 & 13 & 130 & 2015 & [134] \\
\hline GNP & commercial & 2-step & DIW & NO & NO & $0.05-0.1$ & Ultrasonication probe & $\begin{array}{c}\text { THW (KD2 Pro Decagon } \\
\text { device, USA) }\end{array}$ & $20-60$ & 0.1 & 30 & 300 & 2016 & [135] \\
\hline GNP & commercial & 2-step & DIW & NO & NO & $\begin{array}{c}0.025- \\
0.1\end{array}$ & Ultrasonication Probe & $\begin{array}{c}\text { THW (KD2 Pro Decagon } \\
\text { device USA), precision } \pm \\
0.1^{\circ} \mathrm{C} \\
\end{array}$ & $15-70$ & 0.1 & 27 & 270 & 2017 & [136] \\
\hline GO & commercial & 2-step & DIW & NO & NO & $\begin{array}{l}0.001- \\
0.045\end{array}$ & $\begin{array}{l}\text { Ultrasonication probe } \\
350 \mathrm{~W}, 20 \mathrm{kHz}, 45 \mathrm{~min}\end{array}$ & $\begin{array}{c}\text { THW (KD2 Pro Decagon } \\
\text { devices Inc., US) error }< \pm \\
5 \% \text { and random error }< \\
1.2 \%\end{array}$ & $25-50$ & 0.045 & 5 & 111 & 2017 & [137] \\
\hline $\mathrm{rGO}$ & $\begin{array}{l}\text { Hummers' } \\
\text { method }\end{array}$ & 2-step & $\begin{array}{l}\text { DIW:EG } \\
(70: 30)\end{array}$ & $\mathrm{H}_{2}, 200^{\circ} \mathrm{C}$ & NO & $\begin{array}{l}0.076- \\
0.73\end{array}$ & $\begin{array}{l}\text { Intense ultrasonication } \\
\qquad 45 \mathrm{~min}\end{array}$ & THW, uncertainty $<61 \%$ & $10-70$ & 0.73 & 14 & 19 & 2013 & [138] \\
\hline GNP & commercial & 2-step & EG & NO & NO & $\begin{array}{l}0.93- \\
7.4\end{array}$ & $\begin{array}{l}\text { Ultrasonication } 500 \mathrm{~W} \\
25 \mathrm{kH} \text { and probe-type } \\
750 \mathrm{~W}, 20 \mathrm{kHz}\end{array}$ & $\begin{array}{l}\text { THW (LAMBDA, F5 } \\
\text { Technologie, Germany) }\end{array}$ & $10-90$ & 7.4 & 29 & 3.9 & 2014 & [139] \\
\hline $\mathrm{rGO}$ & $\begin{array}{l}\text { Hummers' } \\
\text { method }\end{array}$ & 2-step & $\begin{array}{c}\text { ionic } \\
\text { liquid: } \\
\text { [HMIM]B } \\
\mathrm{F}_{4}\end{array}$ & NO & NO & $\begin{array}{c}0.03 \& \\
0.06\end{array}$ & $\begin{array}{c}\text { Ultrasonic probe, } 25 \mathrm{~W} \\
40 \mathrm{kHz}, 8 \mathrm{~h}\end{array}$ & $\begin{array}{l}\text { TPS (Hot Disk TPS } 2500 \mathrm{~S} \\
\text { Hot Disk AB, Sweden) } \\
\text { accuracy }<3 \%\end{array}$ & $\begin{array}{l}25- \\
200\end{array}$ & 0.06 & 16 & 267 & 2014 & [140] \\
\hline FLG & commercial & 2-step & $\begin{array}{c}\text { ionic } \\
\text { liquid: } \\
\text { [HMIM]B } \\
\mathrm{F}_{4}\end{array}$ & $\mathrm{NH}_{4} \mathrm{BF}_{4}$ & NO & $\begin{array}{l}0.01- \\
0.05\end{array}$ & $\begin{array}{l}\text { Middly stirring (without } \\
\text { sonication) }\end{array}$ & $\begin{array}{l}\text { THP (TPS2500, Hot Disk, } \\
\text { Sweden) }\end{array}$ & $\begin{array}{l}30- \\
150\end{array}$ & 0.05 & 8 & 160 & 2017 & [141] \\
\hline $\mathrm{rGO}$ & $\begin{array}{l}\text { Hummers' } \\
\text { method }\end{array}$ & 2-step & silicon oil & $\begin{array}{c}\text { 3- } \\
\text { glycidoxypr } \\
\text { opyltrimeth } \\
\text { oxysilane } \\
\text { (KH-570)+ } \\
\text { hydrazine }\end{array}$ & NO & $\begin{array}{l}0.01- \\
0.07\end{array}$ & $6 \mathrm{~h}$ in a ultrasonic bath & THW, average of 3 meas. & $20-60$ & 0.07 & 7 & 100 & 2013 & [142] \\
\hline NDG & $\begin{array}{l}\text { Hydrother } \\
\text { mal }\end{array}$ & 2-step & DIW & NO & $\begin{array}{l}\text { Triton X- } \\
100\end{array}$ & $\begin{array}{c}0.01- \\
0.06\end{array}$ & $\begin{array}{l}\text { Ultrasonication probe } 60 \\
\text { min }\end{array}$ & N.A. & $15-40$ & 0.06 & 33 & 550 & 2016 & [143] \\
\hline
\end{tabular}




\begin{tabular}{|c|c|c|c|c|c|c|c|c|c|c|c|c|c|c|}
\hline GNP & commercial & 2-step & DIW & NO & NO & $\begin{array}{c}0.025- \\
0.1\end{array}$ & Ultrasonication probe & $\begin{array}{c}\text { THW (KD2 Pro Decagon } \\
\text { Devices, Inc., Pullman, WA, } \\
\text { USA) }\end{array}$ & $15-40$ & 0.1 & 27 & 270 & 2015 & [144] \\
\hline GNP & commercial & 2-step & DIW & NO & NO & $\begin{array}{c}0.025- \\
0.1 \\
\end{array}$ & $\begin{array}{c}\text { Ultrasonication probe } \\
1200 \mathrm{~W}, 20 \mathrm{kHz}\end{array}$ & $\begin{array}{l}\text { THW (KD2 Pro Decagon } \\
\text { devices) accuracy } \pm 5 \%\end{array}$ & $15-40$ & 0.1 & 27 & 270 & 2015 & [145] \\
\hline rGO & $\begin{array}{l}\text { Hummers' } \\
\text { method }\end{array}$ & 2-step & DIW & $\begin{array}{c}\text { polyphenol } \\
\text { from red } \\
\text { wine }\end{array}$ & NO & $1.9-7.4$ & $\begin{array}{l}\text { sonication bath } \\
\text { (unspecified time) }\end{array}$ & $\begin{array}{l}\text { THW (KD2 Pro Decagon } \\
\text { Devices, USA) accuracy 5\% }\end{array}$ & $15-40$ & 7.4 & 18 & 2.4 & 2016 & [146] \\
\hline NDG & $\begin{array}{l}\text { Hydrother } \\
\text { mal }\end{array}$ & 2-step & DIW & NO & $\begin{array}{l}\text { Triton X- } \\
100\end{array}$ & $\begin{array}{c}0.01- \\
0.06\end{array}$ & $\begin{array}{l}\text { Ultrasonication probe } \\
1200 \mathrm{~W}, 20 \mathrm{kHz}, 60 \mathrm{~min}\end{array}$ & $\begin{array}{c}\text { THW (KD2 Pro Decagon } \\
\text { Devices, USA) accuracy < } 5 \\
\%\end{array}$ & $15-40$ & 0.06 & 35 & 584 & 2014 & [147] \\
\hline GNP & commercial & 2-step & DIW & NO & NO & $\begin{array}{c}0.025- \\
0.1\end{array}$ & $\begin{array}{c}\text { Ultrasonication probe } \\
1200 \mathrm{~W} \text { output power } \\
\text { and a } 20 \mathrm{kHz} \text {. }\end{array}$ & $\begin{array}{l}\text { THW, (KD2 Pro Decagon } \\
\text { Devices, USA) accuracy } 5 \%, \\
\text { average of } 10 \text { meas. }\end{array}$ & $15-40$ & 0.1 & 27 & 270 & 2014 & [148] \\
\hline $\begin{array}{c}\text { nano } \\
\text { poro } \\
\text { us } \\
\text { GE }\end{array}$ & CVD & 2-step & DIW & NO & $\begin{array}{c}\text { Ter- } \\
\text { polymer }\end{array}$ & $\begin{array}{c}0.025- \\
0.1\end{array}$ & Ultrasonic & $\begin{array}{l}\text { THW (KD2 Pro Decagon } \\
\text { Devices) }\end{array}$ & $15-40$ & 0.1 & 4 & 40 & 2016 & [149] \\
\hline GO & $\begin{array}{l}\text { Hummers' } \\
\text { method }\end{array}$ & 2-step & $\begin{array}{l}\text { DIW:EG } \\
(70: 30)\end{array}$ & NO & SDS & $0.1-0.3$ & Ultrasonic probe, $8 \mathrm{~h}$ & $\begin{array}{l}\text { THW (KD2 Pro Decagon } \\
\text { Devices) accuracy } \pm 5 \%\end{array}$ & $30-70$ & 0.3 & 12.6 & 42 & 2020 & [150] \\
\hline GNP & commercial & 2-step & DIW & NO & NO & $\begin{array}{c}0.025- \\
0.1\end{array}$ & $\begin{array}{l}\text { Ultrasonication probe } \\
1200 \mathrm{~W} \text { at } 20 \mathrm{KHz}\end{array}$ & $\begin{array}{l}\text { THW (KD2 Pro Decagon } \\
\text { Devices, USA), error }<5 \%\end{array}$ & $15-40$ & 0.1 & 25 & 250 & 2016 & [151] \\
\hline GNP & commercial & 2-step & DIW & SAS & NO & $3.7-9.25$ & $\begin{array}{c}\text { Ultrasonication probe, } 5 \\
\text { min, } 2 \mathrm{~h} \text { in ice-water } \\
\text { bath }\end{array}$ & $\begin{array}{c}\text { THW (KD2 Pro Decagon } \\
\text { Devices, USA) accuracy } \\
<\% 5\end{array}$ & $15-40$ & 9.25 & 16 & 1.7 & 2020 & [152] \\
\hline GNP & commercial & 2-step & DIW & NO & NO & $0.025-0.1$ & $\begin{array}{l}\text { Ultrasonication probe, } \\
750 \mathrm{~W}, 20 \mathrm{KHz}\end{array}$ & $\begin{array}{c}\text { THW (KD2 Pro Decagon } \\
\text { Devices, USA) accuracy 2- } \\
4 \% \\
\end{array}$ & $15-40$ & 0.1 & 21 & 210 & 2015 & [153] \\
\hline GNP & commercial & 2-step & DIW & GA & NO & 0.093 & $\begin{array}{l}\text { Ultrasonication probe } \\
\text { for } 20 \mathrm{~min}\end{array}$ & $\begin{array}{l}\text { THW (KD2 Pro Decagon } \\
\text { Devices, USA) accuracy } 5 \% \text {, } \\
\text { average of } 20 \text { meas. }\end{array}$ & $20-45$ & 0.093 & 16 & 173 & 2017 & [154] \\
\hline GNP & commercial & 2-step & DIW & GA & NO & $\begin{array}{c}0.025- \\
0.1\end{array}$ & $\begin{array}{l}\text { Ultrasonicated for } 15 \\
\text { min with sonication } \\
\text { probe }\end{array}$ & $\begin{array}{l}\text { THW (KD2 PRO Decagon } \\
\text { Devices, USA), accuracy } \\
5 \% \text {, average of } 20 \text { meas. }\end{array}$ & $20-45$ & 0.1 & 17 & 170 & 2017 & [155] \\
\hline GNP & commercial & 2-step & DIW & $\begin{array}{c}\text { eugenol, } \\
\text { eugenyl } \\
\text { acetate and } \\
\text { b- } \\
\text { caryophylle } \\
\text { ne (clove- } \\
\text { treated) }\end{array}$ & NO & $\begin{array}{c}0.025- \\
0.1\end{array}$ & $\begin{array}{l}\text { Ultrasonication for } 10 \\
\min \end{array}$ & $\begin{array}{l}\text { THW (KD2 Pro device) } \\
\text { accuracy } \pm 5 \%\end{array}$ & $20-45$ & 0.1 & 15 & 150 & 2018 & [156] \\
\hline
\end{tabular}




\begin{tabular}{|c|c|c|c|c|c|c|c|c|c|c|c|c|c|c|}
\hline GNP & commercial & 2-step & DIW & TEA & NO & $\begin{array}{c}0.025- \\
0.1\end{array}$ & $\begin{array}{l}\text { Ultrasonication, } 450 \mathrm{~W} \\
\text { pulsed mode } 2 \mathrm{~S} \text { on/off }\end{array}$ & $\begin{array}{c}\text { THW ( KD2 Pro Decagon } \\
\text { devices, Inc., USA), } \\
\text { accuracy }<5 \% \text {, accuracy } \\
0.1^{\circ} \mathrm{C}, 8 \text { meas. }\end{array}$ & $20-40$ & 0.1 & 19 & 190 & 2016 & [38] \\
\hline GNP & commercial & 2-step & DIW & NO & Gum Arabic & 0.1 & $\begin{array}{c}\text { Ultrasonication probe, } \\
750 \mathrm{~W}, 20 \mathrm{kHz}, 15,30, \\
60,90 \text { and } \\
120 \mathrm{~min} .\end{array}$ & $\begin{array}{l}\text { THW, (KD2 Pro Decagon } \\
\text { devices, Inc., USA) } \\
\text { accuracy }<5 \% \text {, average of } \\
8 \text { meas. }\end{array}$ & $20-40$ & 0.1 & 10 & 100 & 2016 & [106] \\
\hline GQD & CVD & 2-step & DIW & NO & NO & $0.05-0.5$ & $\begin{array}{l}\text { Ultrasonic bath for } 15 \\
\text { min }\end{array}$ & $\begin{array}{c}\text { THW (KD2 Pro Decagon } \\
\text { Devices Inc.; USA) error } \pm \\
0.05 \mathrm{~W} / \mathrm{mK}\end{array}$ & $10-50$ & 0.5 & 34 & 68 & 2019 & [157] \\
\hline GNP & commercial & 2-step & $\begin{array}{l}\text { DIW:EG } \\
(70: 30)\end{array}$ & NO & DOC & $\begin{array}{c}0.19- \\
0.93\end{array}$ & $\begin{array}{l}\text { Utrasonication probe, } \\
700 \mathrm{~W} 20 \mathrm{kHz} \text { during } 2 \mathrm{~h}\end{array}$ & $\begin{array}{c}\text { THW (KD2 Pro Decagon } \\
\text { Devices Inc, USA), } \\
\text { uncertainty } \pm 5.0 \%(0.2-2 \\
\text { W/m K) }\end{array}$ & $30-50$ & 0.93 & 20 & 21.6 & 2017 & [158] \\
\hline GNP & commercial & 2-step & $\begin{array}{l}\text { DIW:EG } \\
(70: 30)\end{array}$ & NO & DOC & $\begin{array}{l}0.002- \\
0.8\end{array}$ & $\begin{array}{l}\text { Utrasonication probe, } \\
700 \mathrm{~W} 20 \mathrm{kHz}, 2 \mathrm{~h}\end{array}$ & $\begin{array}{c}\text { THW (KD2 Pro Decagon } \\
\text { Devices, USA), uncertainty } \\
\pm 5.0 \%(0.2-2 \text { Wm- } 1 \mathrm{~K}-1) \\
\text { average of } 10 \text { meas. } \\
\end{array}$ & $30-50$ & 0.8325 & 17 & 20.4 & 2017 & [159] \\
\hline GNP & commercial & 2-step & DIW & NO & DOC & $\begin{array}{c}0.002- \\
0.8\end{array}$ & Ultrasoication probe $2 \mathrm{~h}$ & $\begin{array}{c}\text { THW (KD2 Pro Decagon } \\
\text { Devices, Inc, USA) } \\
\text { uncertainty }< \pm 5.0 \%(0.2 \text { - } \\
2 \mathrm{~W} / \mathrm{m} \mathrm{K})\end{array}$ & $30-50$ & 0.925 & 27 & 29 & 2016 & [160] \\
\hline GNP & commercial & 2-step & DIW & $\begin{array}{l}\text { oxidation } \\
\text { with } \mathrm{H}_{2} \mathrm{O}_{2} \\
\text { and } \\
\text { treatment } \\
\text { with xylitol } \\
\text { and citric } \\
\text { acid }\end{array}$ & NO & 0.1 & $\begin{array}{l}\text { Stirring } 30 \mathrm{~min}, \mathrm{RT} . \\
\text { Sonication } 1 \mathrm{~h}\end{array}$ & $\begin{array}{c}\text { THW (KD2 Pro Decagon } \\
\text { devices, USA), error < } \\
\pm 0.9 \%\end{array}$ & $20-60$ & 0.1 & 16 & 160 & 2018 & [161] \\
\hline $\begin{array}{l}\mathrm{HFG} \\
\mathrm{O}\end{array}$ & $\begin{array}{c}\text { from } \\
\text { fuorinated } \\
\text { graphite } \\
\text { polymer } \\
\end{array}$ & 2-step & NMP & NO & NO & $\begin{array}{c}0.01- \\
0.10\end{array}$ & sonication probe $6 \mathrm{~h}$ & $\begin{array}{l}\text { THW (KD2 Pro Decagon } \\
\text { Device). } 6 \text { meas. }\end{array}$ & $20-40$ & 0.1 & 18 & 180 & 2014 & [162] \\
\hline GO & commercial & 2-step & DIW & NO & NO & $\begin{array}{l}0.001- \\
0.045\end{array}$ & $\begin{array}{l}\text { Ultrasonication probe } \\
350 \mathrm{~W}, 20 \mathrm{kHz}, 45 \mathrm{~min}\end{array}$ & $\begin{array}{l}\text { THW (KD2 Pro Decagon } \\
\text { devices Inc., US) }\end{array}$ & $25-50$ & 0.045 & 5 & 111 & 2016 & [163] \\
\hline GNP & commercial & 2-step & DIW & NO & NO & $\begin{array}{c}0.00025- \\
0.005\end{array}$ & $\begin{array}{l}\text { Ultrasonication probe, } \\
665 \mathrm{~W}, 20 \mathrm{Khz}, 1 \mathrm{~h}\end{array}$ & $\begin{array}{l}\text { THW (KD2Pro Decagon } \\
\text { devices Inc., US) }\end{array}$ & $25-50$ & 0.005 & 6 & 1200 & 2016 & [164] \\
\hline GNP & $\begin{array}{c}\text { commercial } \\
\mathrm{e}\end{array}$ & 2-step & $\begin{array}{l}\text { Havoline } \\
{ }_{\circledast}{ }^{\circ} \\
\text { XLC: } \text { wate } \\
\text { r (50:50) }\end{array}$ & $\begin{array}{l}\text { polycarbox } \\
\text { ylate } \\
\text { chemically } \\
\text { modified }\end{array}$ & SDBS & $0.25-1$ & $\begin{array}{c}\text { Stirring \& } \\
\text { ultrasonication } 200 \mathrm{~W}, \\
20 \mathrm{kHz}, 240 \mathrm{~min}\end{array}$ & $\begin{array}{c}\text { THW (KD2 Pro Decagon } \\
\text { Devices, USA), uncertainty } \\
<3 \%\end{array}$ & $20-70$ & 1 & 6.6 & 6.6 & 2019 & [114] \\
\hline
\end{tabular}




\begin{tabular}{|c|c|c|c|c|c|c|c|c|c|c|c|c|c|c|}
\hline GO & $\begin{array}{l}\text { Hummers' } \\
\text { method }\end{array}$ & 2-step & DIW & NO & NO & $\begin{array}{c}0.005- \\
0.02\end{array}$ & $\begin{array}{c}\text { Ultrasonicated during } 30 \\
\text { min. }\end{array}$ & $\begin{array}{c}\text { THW (KD2 Pro Decagon, } \\
\text { Canada) }\end{array}$ & $20-70$ & 0.02 & 17 & 830 & 2016 & [165] \\
\hline $\mathrm{rGO}$ & $\begin{array}{l}\text { Hummers' } \\
\text { method }\end{array}$ & 2-step & $\begin{array}{c}\text { ionic } \\
\text { liquid: } \\
\text { ([HMIM] } \\
\left.\mathrm{BF}_{4}\right)\end{array}$ & NO & NO & $\begin{array}{c}0.03 \& \\
0.06\end{array}$ & $\begin{array}{c}\text { Ultrasonication } 100 \mathrm{~W} \text {, } \\
40 \mathrm{kHz}, 8 \mathrm{~h} \& \\
\text { ultrasonication probe } 25 \\
\text { W, } 2 \mathrm{~min}\end{array}$ & $\begin{array}{l}\text { TPS (Hot Disk TPS } 2500 \mathrm{~S}, \\
\text { Hot Disk AB, Gothenburg, } \\
\text { Sweden) }\end{array}$ & $\begin{array}{l}25- \\
200\end{array}$ & 0.06 & 16 & 267 & 2012 & [166] \\
\hline GO & $\begin{array}{l}\text { Hummers' } \\
\text { method }\end{array}$ & 2-step & DIW & NO & NO & $0.5-1.5$ & $\begin{array}{c}\text { Stirring } 1 \mathrm{~h} \mathrm{\&} \\
\text { ultrasonication } 60 \mathrm{~min}\end{array}$ & $\begin{array}{c}\text { THW (KD2 Pro Decagon), } \\
\text { error }<1 \%\end{array}$ & $20-60$ & 1.5 & 29 & 19 & 2019 & [167] \\
\hline GNP & commercial & 2-step & DIW & $\begin{array}{l}\text { oxidation } \\
\text { with } \mathrm{HNO}_{3} \\
\text { and } \mathrm{H}_{2} \mathrm{SO}_{4} \\
\text { at } 1: 3 \text { ratio }\end{array}$ & NO & $0.02-0.1$ & Ultrasonic bath $3 \mathrm{~h}$. & $\begin{array}{l}\text { THW (KD2 pro Decagon, } \\
\text { USA), } 16 \text { meas. } 4 \mathrm{~h}\end{array}$ & $20-40$ & 0.1 & 12 & 120 & 2016 & [168] \\
\hline GO & $\begin{array}{l}\text { Hummers' } \\
\text { method }\end{array}$ & 2-step & $\begin{array}{l}\text { liquid } \\
\text { paraffin }\end{array}$ & NO & NO & $1.9-9.3$ & $\begin{array}{l}\text { Stirring \& sonication, } 40 \\
\mathrm{kHz}, 150 \mathrm{~W}, 3 \mathrm{~h}\end{array}$ & THW, accuracy $<1 \%$ & $10-60$ & 9.3 & 76 & 8.2 & 2010 & [169] \\
\hline GO & $\begin{array}{l}\text { Hummers' } \\
\text { method }\end{array}$ & 2-step & EG & NO & NO & $1.9-9.3$ & $\begin{array}{l}\text { Stirring \& sonication } 40 \\
\mathrm{kHz}, 150 \mathrm{~W}\end{array}$ & THW, accuracy $< \pm 1 \%$ & $10-60$ & 9.3 & 58 & 6.3 & 2010 & [170] \\
\hline rGO & $\begin{array}{l}\text { Hummers' } \\
\text { method }\end{array}$ & 2-step & EG & NO & SDBS & $1.9-9.3$ & $\begin{array}{l}\text { Stirring \& sonicating } 40 \\
\mathrm{kHz}, 150 \mathrm{~W}\end{array}$ & $\begin{array}{c}\text { THW. A transient short } \\
\text { hot-wire (SHW) accuracy } \\
1 \%\end{array}$ & $10-60$ & 9.3 & 90 & 9.7 & 2011 & [171] \\
\hline $\mathrm{rGO}$ & $\begin{array}{l}\text { Hummers' } \\
\text { method }\end{array}$ & 2-step & DIW & NO & NO & $0.02-0.1$ & Ultrasonication probe & THW & $20-60$ & 0.1 & 17 & 170 & 2017 & [172] \\
\hline GNP & $\begin{array}{c}\text { Commercia } \\
\mid\end{array}$ & 2-step & DIW & NO & NO & $\begin{array}{c}0.0025- \\
0.1\end{array}$ & $\begin{array}{l}\text { Ultrasonication probe } \\
120 \mathrm{~W}, 40 \mathrm{kHz}, 2 \mathrm{~h}\end{array}$ & $\begin{array}{c}\text { THW (KD2 Pro Decagon), } \\
\text { accuracy }< \pm 5 \%\end{array}$ & $15-40$ & 0.1 & 16 & 160 & 2018 & [173] \\
\hline
\end{tabular}


The present review proposes a comparative analysis of the TC performance of the nanofluids through the introduced new parameter $\mathcal{P}_{\mathcal{T C}}$. The first aspect analyzed is the TC enhancements at $30^{\circ} \mathrm{C}, \mathrm{TCe}_{30}$, for all the GNFs, and the corresponding $\mathcal{P}_{\mathcal{T C}}$ (Figure 4). Figure 4a represents $\mathrm{TCe}_{30}$ of GNFs in percentage, reported from 2010 until today. For sake of clarity, each year is represented by a different color. High TC enhancements were in 2010 and 2011, with the higher top 3 values (in the $55-90 \%$ range) among them. Such TC enhancement values for GNFs were not hitherto reached in the community. A sudden decrease in $\mathrm{TCe}_{30}$ (below $20 \%$ ) is observable in 2012 and 2013. Since 2014, a little recover in $\mathrm{TC}$ enhancement is evident with $\mathrm{TCe}_{30}$ found in the $20-30 \%$ range. Such TC enhancements are quite good values even if they are lower than the $55-90 \%$ enhancement range for the first studies. This range of TC enhancements is also observed until the most recent years. 

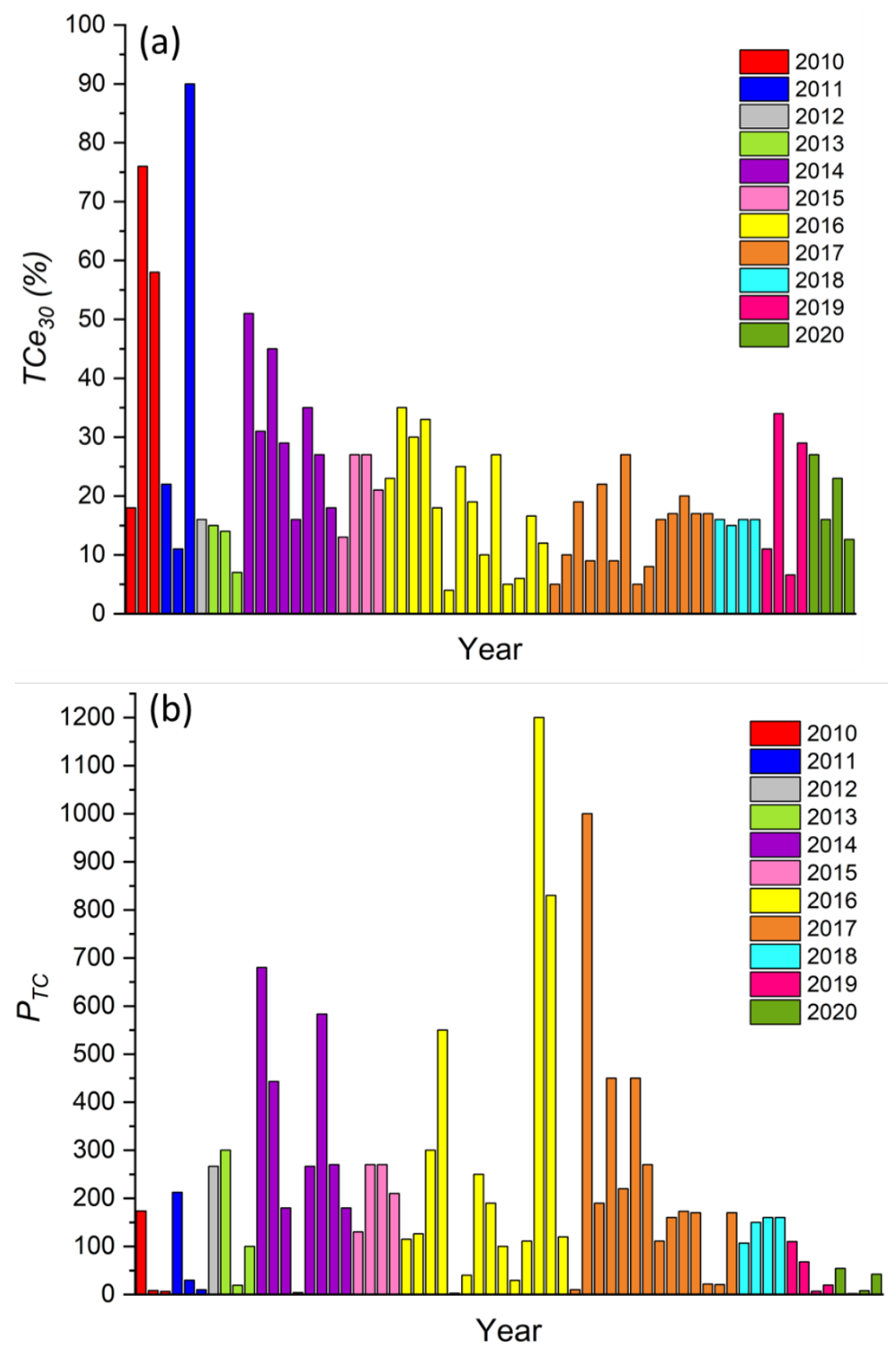

Figure 4 a) TC enhancement at $30^{\circ} \mathrm{C}$ for $\mathrm{GNF}\left(\mathrm{TCe}_{30}\right)$ and b) TC performance parameter $\left(P_{T C}\right)$ as a function of the publication year for each study.

As shown in the Figure $4 \mathrm{~b}, \mathrm{TCe}_{30}(\%)$ was divided by the GE concentration (wt.\%) to obtain $\mathcal{P}_{\text {TC }}$ (equation 2) so that the TC performances for all the prepared nanofluids can be reported in the same graph to be compared. Obviously, higher quantities of GE lead to higher 
TC values in the resulting nanofluid. However, it is interesting to consider to what extent the GE concentration impacts the TC of the corresponding nanofluid.

At first sight, it is noticeable that the values are much more spread in Figure $4 \mathrm{~b}$ than for the representation in Figure 4a. This spreading effect is even more pronounced in figure $4 \mathrm{~b}$ because of higher scale amplitude. This effect was expected since the GE concentration range is relatively large from 0.005 to $9.3 \mathrm{wt} . \%$ for the extreme values. Contrary to what it is observed in figure $4 \mathrm{a}$, figure $4 \mathrm{~b}$ shows maximum values of $\mathcal{P}_{\text {TC }}$ shifted to more the recent years, from 2010 - 2011 to 2016 - 2017. Moreover, by taking into account the amount of GE (figure $4 \mathrm{~b}$ ), the highest values of $\mathcal{P}_{\mathcal{T C}}$ are among the lowest ones for $\mathrm{TC}_{30}$ in figure $4 \mathrm{a}$. That confirms that the behavior related to the TC performance is mainly governed by the GE amount, especially for the lowest GE concentrations. For the highest $\mathcal{P}_{\mathcal{T C}}$ values, the maximum reported TC enhancements (not so high however), the GE amount inducing these properties was very low: 6,10 and $17 \%$ of TC enhancement for $0.005[164], 0.01[123]$ and $0.02[165]$ wt. $\%$ of GE, respectively leading to $\mathcal{P}_{\tau C}$ of 1200,1000 and 830, respectively. Apart from these three highest $\mathcal{P}_{\text {TC }}$ values, TC performances of GNF reported these recent years appears to be among the lowest ones. The reported high $\mathrm{TCe}_{30}$ are indeed due to the high GE concentration used; tendency that has changed during 2013 to 2017 and tends to arise again in more recent years.

In the following, this review proceeds to analyze in more detail the influence of the mostly used GE derivative materials and the chemical modification strategy used in nanofluid preparation according to the existing literature. The use of defective GE or additives is believed to be responsible of TC lessening (Section II.4). This is the reason why $\mathcal{P}_{\tau C}$ was examined as a function of the main types of GE and the eventual applied chemical modification (figure 5). Among the types of GE (GNP (including GF), GO, rGO. NDG, GQD, 
HFGO and FLG, cf. Table 2), GNP, GO and rGO for which the number of published works is relatively high have been considered for analysis.

Figure 5a shows the previously introduced TC performance parameter $\mathcal{P}_{\mathcal{T C}}$ as a function of the $\mathrm{TCe}_{30}$ and type of both GE and the chemical modification. In the figure, the GE derivatives are represented by different colors and different symbols are used to distinguish among the type of the chemical modification applied.

Even if the data reported in the figure are quite dispersed, regardless of the GE nature, it is clearly noticeable that many points belong to a straight line tendency (gray pointed line was plotted as visual guide, figure 5a). This trend may originate from a sort of standardized behavior applicable to a significant part of the developed nanofluids, about $50 \%$ of them. The nanofluids located on this straight line can be made with GNP, GO or rGO not functionalized, covalently or non-covalently functionalized, the amount of GE required to increase TC of a certain percentage is the same. An augmentation of TC of $10 \%$ results from an addition of 0.1 wt.\% of GE within the base fluid for these nanofluids. 

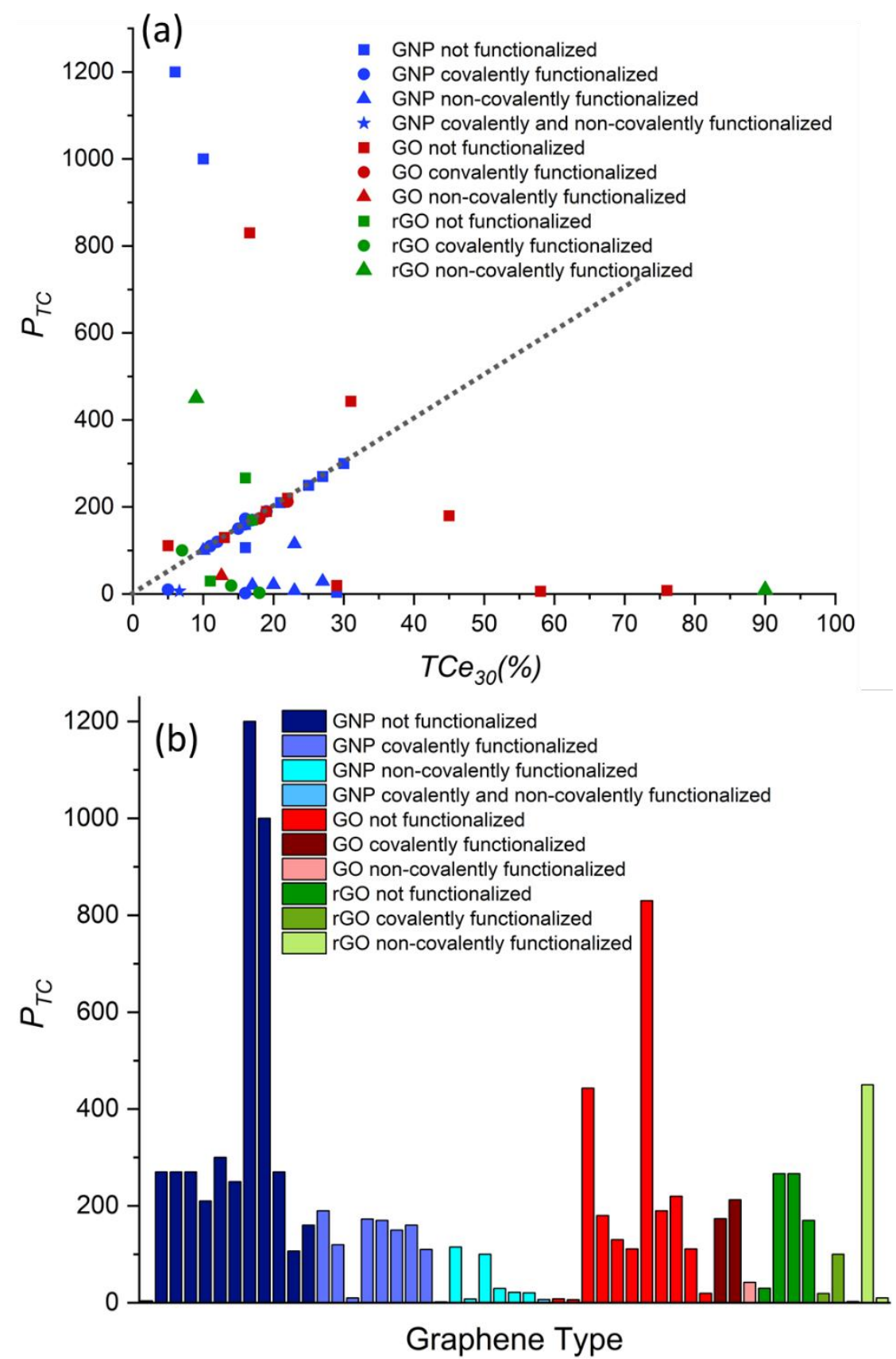

Figure 5 a) TC performance parameter $P_{T C}$ as a function of the TC enhancement at $30^{\circ} \mathrm{C} \mathrm{TCe_{30 } .}$ ) $\mathrm{TC}$ performance parameter $P_{T C}$ as a function of the GE derivative used in the GNF.

There are as well performances of GNFs located below and above this linear trend. The GNFs $P_{T C}$ with values below this particular trend do not show any specificity in the kind of the employed GE nature or the applied chemical modification. It is clear that for these GNF performances a higher GE concentrations were required to induce the reported TC 
enhancements, especially for highest TC enhancements up 50-90\%[169-171] since the performance parameter is below 10 .

The highest $P_{T C}$ values correspond to quite low measured $\mathrm{TCe}_{30}$, below $20 \%$ with the two highest $P_{T C}$ related to GNFs prepared with non-functionalized GNPs [123,164]. For these works, $\mathrm{TCe}_{30}$ is as weak as 6 and $10 \%$, respectively for the work by Nika et al.[123] and Vakili et al.[164]. They have indeed used very low GE concentration, i.e. 0.01 and 0.005 wt.\%, respectively. Interestingly for these GNP-based nanofluids, a very low amount of GNPs has induced remarkable TC enhancements. For the highest $P_{T C}$ reported (1200\%/wt.\% of GE), $10 \%$ of TC increase has been induced by only 0.005 wt. $\%$ of GNP. That means that the ability of these GNPs to enhance nanofluid TC is increased by a factor of 12 compared to the proportional trend observed. Such performance in GNFs has however seldom been reported. And unfortunately, such high $P_{T C}$, in the $20-50 \%$ improvement range for example, cannot be found in literature. It can be hypothesized that GNPs showing the best TC enhancement can only be dispersed at low concentration in the base fluid.

The $P_{T C}$ of GNP-based nanofluid are relatively high in average compared with that of GO- and rGO-based nanofluids. Obviously, when the researchers would like to improve the nanofluid stability by covalent functionalization by using GO or rGO instead of GNPs, $P_{T C}$ is decreased. And, $P_{T C}$ values from nanofluids prepared with covalent and non-covalent $\mathrm{GO} / \mathrm{rGO}$ are much lower than those observed for $\mathrm{GO}$ and $\mathrm{rGO}$ without post-synthesis functionalization, in average. Surprisingly, GO- and rGO-based nanofluids, including after additional functionalization, show higher $P_{T C}$ in average compared with the GNFs prepared with chemically modified GNPs. Functionalized GNPs, which bear a much smaller number of defects than GO (and rGO) would lead to highest $P_{T C}$ even after functionalization. 
Another unexpected result concerns the weak difference of $P_{T C}$ of GO- and rGO-based nanofluids. The carbon network recovering of $\mathrm{rGO}$ after reduction would increase the intrinsic TC of rGO compared to GO. However, improvement regarding $P_{T C}$ of $\mathrm{rGO}$ compared to GO is not obvious (Figure $5 b$ ).

Any chemical modification applied to GNPs, i.e. addition of surfactant (non-covalent) or introduction/presence of functional groups (covalent), shows a decrease in nanofluid TC. For non-functionalized GNPs, $P_{T C}$ is in the 1000-1200 range (blue square) and the thermal conductivity performance factor is 100 times lower (blue triangle, circle and star) when either a covalent or non-covalent approach is applied. Pristine GNPs are highly hydrophobic and without chemical modification, they can be only dispersed at weak concentration in the base fluid (with high sonication power method). Their chemical modification allows to better disperse them. However, the conducted analysis from Figure 5 shows that when considering $P_{T C}$, the increase in TC due to the higher content of chemically modified GNPs used is not balanced by their consequent reduction in intrinsic TC due to the structural defects introduced and/or the thermal resistance because of the presence of the surfactant coating. Contrary to GNPs, GO and rGO have already functionalized groups at their surface. As already mentioned, the reduction reaction applied to GO to produce rGO allows a certain recovering of the physical properties, including thermal conductivity (Table 1). This is the reason why chemical modification is less encountered for GO-based nanofluid (or rGO-based nanofluid) preparation. Even if the decrease in thermal conductivity of GO compared to GNP is very significant (Table 2), $P_{T C}$ of GO-based nanofluids is relatively comparable to that of GNPbased nanofluids. The better dispersion expected for GO certainly favorably impacts the nanofluid TC. This finding reveals the complexity and the interplay of the factors affecting TC of graphene-based nanofluids, among which dispersion is an important aspect to consider [174-176]. rGO is expected to show an intermediate (between GNP and GO) behavior since 
its transport properties are increased after reduction. Even if, the rate of reduction is difficult to control $[47,177]$, the remaining amount of functional groups helps to disperse them in the base fluids. Like for GO, rGO does not necessarily need any additional chemical modification or high sonication energy dispersion procedures to be used for nanofluid preparation. Moreover, such rGO-based nanofluids have shown interesting $P_{T C}$ (figure $5 \mathrm{~b}$ ). A compromise between the reduction rate and the dispersion ability has certainly to be find for upcoming nanofluid development. When surfactants have been added to improve the dispersion state of rGO in the work from Chen et al., a quite good $P_{T C}(450)$ has been obtained [125].

\section{Conclusions and outlook}

This review covers the development of GNFs and their TC enhancement. The potential of such nanofluids to be used as heat transfer fluids is widely recognized. The different types of GE nanomaterials used for nanofluid preparation are described along with their characteristics and the chemical approaches applied to assist their dispersion in the selected base fluid. The chemical modifications of GE have been reported to potentially strongly influence their intrinsic TC and consequently those of the nanofluid themselves. It appears that many GE systems have been developed and their efficiency is discussed in this review. To this end, a TC performance parameter of GNFs, $\mathcal{P}_{\mathcal{T C}}$ is proposed. $\mathcal{P}_{\mathcal{T C}}$ allows to relate the TC enhancement of a given nanofluid to the amount of GE used to get this rate of increase. Moreover, this new parameter, never used before, is useful to provide a performance scale and compare the efficiency of the GNFs. The present work allows a rigorous comparative analysis of the GNFs regarding their TC efficiency. The most important findings from this review along with the challenges and future directions are as follows: 


\section{V.1 Results}

- Over the 10-year of research on GNFs, the highest TC enhancements have been reported in 2010-2011. Since that time, the greater TC enhancements tend to remain stable in the $20-30 \%$ range.

- $\mathcal{P}_{\mathcal{T C}}$ a universal TC performance parameter, is simply calculated by dividing the TC enhancement by the respective amount of GE required to reach the reported TC. Compared to TC enhancement, the best $\mathcal{P}_{\mathcal{T C}}$ are found to be shifted to more recent years, from 2010 - 2011 to 2016 - 2017. In 3-4 recent years, no significant TC performance improvement has been reported in literature.

- A general tendency (followed by around $50 \%$ of the reported studies) showing an augmentation of TC of $10 \%$ with addition of 0.1 wt.\% of GE in GNF has been evidenced. The GNFs whose $P_{T C}$ are below this reference have been prepared with a high amount of GE compared to other works. Such conditions may result in GNF viscosity rise which is prejudicial to their further use in circulating systems.

- The best GNFs whose $\mathcal{P}_{\text {TC }}$ is situated far above this trend (0.1 wt. $\%$ of GE enhancing TC of greater than $10 \%$ ) were prepared with the lowest GE concentrations among the published studies.

- Regarding the type of GE, $P_{T C}$ of GNP-based nanofluids are found to be higher in average compared with GNFs prepared with GO or rGO. And $\mathcal{P}_{\mathcal{T C}}$ of GNF-based nanofluids is reduced after any chemical modification of GNF by non-covalent or covalent functionalization. $P_{T C}$ for the modified GNPs are much lower than those observed for $\mathrm{GO}$ and $\mathrm{rGO}$ without post-synthesis functionalization.

\section{V.2 Recommendations}


- Study of TC of the GE derivatives themselves (i.e. GNP, GF, GO and rGO) used to design GNFs is of great interest to better understand the interdependency between the intrinsic TC of GE at the nanometer scale and the TC measured for the GNFs. Such investigations are poorly found in literature. For example, characterization by scanning transmission electron microscopy (STEM) and electron energy-loss spectroscopy (EELS) usually conducted on CVD grown GE[178] applied to GNP, GO and rGO type would be useful to fill the lack of knowledge currently existing between the nano and the microscale in nanofluid properties.

- More generally, an in-depth characterization to know the physical and structural properties of the GE nanosheets chosen for nanofluid designing would considerably help to go further in the optimization of TC performances. For this purpose, the implementation of advanced characterization methods to study GNF, GO and rGO nanosheets is essential since the structural defects play a significant role in the diffusion of phonons within such nanomaterials. The intrinsic TC of these GE types implying the introduction of functional groups (covalent functionalization) must be investigated. Another related aspect which requires more attention concerns the examination of the interfacial phenomena taking place at the molecular scale when surfactants are adsorbed at the GE surface; in particular regarding phonon scattering at this complex interface and the resulting interface thermal resistance.

- Stability is another aspect to consider when developing nanofluids and especially GNFs. Study of GNF stability is relatively complex since optical techniques such as UV-visible spectroscopy requires dilution of the nanofluid. Moreover, such optical techniques and Zeta potential as well, are carried out to investigate the stability of GNFs under static conditions while most of GNF applications involve fluid flowing. 
An important research priority is the investigation of GNF stability under conditions mimicking the envisaged utilizations under heating, flowing and pressure eventually.

\section{Declaration of competing interest}

The authors declare that they have no known competing financial interests or personal relationships that could have appeared to influence the work reported in this paper.

\section{Acknowledgments}

This work received financial support from the Lorraine Université d'Excellence", LUE International program. 


\section{References}

[1] Choi SUS, Eastman JA. Enhancing Thermal Conductivity of Fluids with Nanoparticles. Conference: 1995 International Mechanical Engineering Congress and Exhibition, San Francisco, CA (United States), 12-17 Nov 1995; Other Information: PBD: Oct 1995 1995:8.

[2] Angayarkanni SA, Philip J. Review on thermal properties of nanofluids: Recent developments. Advances in Colloid and Interface Science 2015;225:146-76. https://doi.org/10.1016/j.cis.2015.08.014.

[3] Solangi KH, Kazi SN, Luhur MR, Badarudin A, Amiri A, Sadri R, et al. A comprehensive review of thermo-physical properties and convective heat transfer to nanofluids. Energy 2015;89:106586. https://doi.org/10.1016/j.energy.2015.06.105.

[4] Philip J, Shima PD. Thermal properties of nanofluids. Advances in Colloid and Interface Science 2012;183-184:30-45. https://doi.org/10.1016/j.cis.2012.08.001.

[5] Ahmadi MH, Mirlohi A, Nazari MA, Ghasempour R. A review of thermal conductivity of various nanofluids. J Mol Liq 2018;265:181-8. https://doi.org/10.1016/j.molliq.2018.05.124.

[6] Hemmat Esfe M, Bahiraei M, Mir A. Application of conventional and hybrid nanofluids in different machining processes: A critical review. Advances in Colloid and Interface Science 2020;282:102199. https://doi.org/10.1016/j.cis.2020.102199.

[7] Nazari MA, Ghasempour R, Ahmadi MH, Heydarian G, Shafii MB. Experimental investigation of graphene oxide nanofluid on heat transfer enhancement of pulsating heat pipe. International Communications in Heat and Mass Transfer 2018;91:90-4. https://doi.org/10.1016/j.icheatmasstransfer.2017.12.006.

[8] Yang L, Huang J, Zhou F. Thermophysical properties and applications of nano-enhanced PCMs: An update review. Energy Conversion and Management 2020;214:112876. https://doi.org/10.1016/j.enconman.2020.112876.

[9] Yang L, Jiang W, Ji W, Mahian O, Bazri S, Sadri R, et al. A review of heating/cooling processes using nanomaterials suspended in refrigerants and lubricants. International Journal of Heat and Mass Transfer 2020;153:119611. https://doi.org/10.1016/j.ijheatmasstransfer.2020.119611.

[10] Li Y, Zhou J, Tung S, Schneider E, Xi S. A review on development of nanofluid preparation and characterization. Powder Technology 2009;196:89-101. https://doi.org/10.1016/j.powtec.2009.07.025.

[11] Saidur R, Leong KY, Mohammad HA. A review on applications and challenges of nanofluids. Renewable and Sustainable Energy Reviews 2011;15:1646-68. https://doi.org/10.1016/j.rser.2010.11.035.

[12] Kalbani KSA, Alam MS, Rahman MM. Finite element analysis of natural convective heat transfer flow of nanofluids inside a tilted square enclosure in the presence of oriented magnetic field. American Journal of Heat and Mass Transfer 2016;3:186-224. https://doi.org/10.7726/ajhmt.2016.1012.

[13] Kedzierski MA. Viscosity and density of $\mathrm{CuO}$ nanolubricant. International Journal of Refrigeration 2012;35:1997-2002. https://doi.org/10.1016/j.ijrefrig.2012.06.012.

[14] Zhang Q, Zhang K, Xu D, Yang G, Huang H, Nie F, et al. CuO nanostructures: Synthesis, characterization, growth mechanisms, fundamental properties, and applications. Progress in Materials Science 2014;60:208-337. https://doi.org/10.1016/j.pmatsci.2013.09.003.

[15] Liu M, Lin MC, Wang C. Enhancements of thermal conductivities with $\mathrm{Cu}, \mathrm{CuO}$, and carbon nanotube nanofluids and application of MWNT/water nanofluid on a water chiller system. Nanoscale Res Lett 2011;6:297. https://doi.org/10.1186/1556-276X-6-297. 
[16] Mohamad MS, Zainuddin H, Ab Ghani S, Chairul IS. AC Breakdown Voltage and Viscosity of Palm Fatty Acid Ester (PFAE) Oil-based Nanofluids. Journal of Electrical Engineering and Technology 2017;12:2333-41. https://doi.org/10.5370/JEET.2017.12.6.2333.

[17] Yildiz A, Lisesivdin SB, Kasap M, Mardare D. Electrical properties of TiO2 thin films. Journal of Non-Crystalline Solids 2008;354:4944-7. https://doi.org/10.1016/j.jnoncrysol.2008.07.009.

[18] Feng $X$, Huang $X$, Wang $X$. Thermal conductivity and secondary porosity of single anatase TiO 2/nanowire. Nanotechnology 2012;23:185701. https://doi.org/10.1088/09574484/23/18/185701.

[19] Peters DW. Thermoelectric power of single-crystal aluminum oxide. Journal of Physics and Chemistry of Solids 1966;27:1560-2. https://doi.org/10.1016/0022-3697(66)90155-7.

[20] Bansal NP, Zhu D. Thermal conductivity of zirconia-alumina composites. Ceramics International 2005;31:911-6. https://doi.org/10.1016/j.ceramint.2004.09.018.

[21] Abdalla S, Al-Marzouki F, Al-Ghamdi AA, Abdel-Daiem A. Different Technical Applications of Carbon Nanotubes. Nanoscale Research Letters 2015;10:358. https://doi.org/10.1186/s11671-015-1056-3.

[22] Che J, Çagin T, Goddard WA. Thermal conductivity of carbon nanotubes. Nanotechnology 2000;11:65-69. https://doi.org/10.1088/0957-4484/11/2/305.

[23] Fahmy Taha MH, Ashraf H, Caesarendra W. A Brief Description of Cyclic Voltammetry Transducer-Based Non-Enzymatic Glucose Biosensor Using Synthesized Graphene Electrodes. Applied System Innovation 2020;3:32. https://doi.org/10.3390/asi3030032.

[24] Ogino I, Fukazawa G, Kamatari S, Iwamura S, Mukai SR. The critical role of bulk density of graphene oxide in tuning its defect concentration through microwave-driven annealing. Journal of Energy Chemistry 2018;27:1468-74. https://doi.org/10.1016/j.jechem.2017.09.010.

[25] Sundar LS, Shusmitha K, Singh MK, Sousa ACM. Electrical conductivity enhancement of nanodiamond-nickel (ND-Ni) nanocomposite based magnetic nanofluids. International Communications in Heat and Mass Transfer 2014;57:1-7. https://doi.org/10.1016/j.icheatmasstransfer.2014.07.003.

[26] Banisharif A, Estellé P, Rashidi A, Van Vaerenbergh S, Aghajani M. Heat transfer properties of metal, metal oxides, and carbon water-based nanofluids in the ethanol condensation process. Colloids and Surfaces A: Physicochemical and Engineering Aspects 2021;622:126720. https://doi.org/10.1016/j.colsurfa.2021.126720.

[27] Bohne D, Fischer S, Obermeier E. Thermal, Conductivity, Density, Viscosity, and PrandtlNumbers of Ethylene Glycol-Water Mixtures. Berichte Der Bunsengesellschaft Für Physikalische Chemie 1984;88:739-42. https://doi.org/10.1002/bbpc.19840880813.

[28] Aberoumand S, Jafarimoghaddam A. Experimental study on synthesis, stability, thermal conductivity and viscosity of $\mathrm{Cu}$-engine oil nanofluid - ScienceDirect. Journal of the Taiwan Institute of Chemical Engineers 2020;71:315-22. https://doi.org/10.1016/j.jtice.2016.12.035.

[29] Fedele L, Colla L, Bobbo S. Viscosity and thermal conductivity measurements of water-based nanofluids containing titanium oxide nanoparticles. International Journal of Refrigeration 2012;35:1359-66. https://doi.org/10.1016/j.ijrefrig.2012.03.012.

[30] Sharifpur M, Tshimanga N, Meyer JP, Manca O. Experimental investigation and model development for thermal conductivity of $\alpha$-Al2O3-glycerol nanofluids. International Communications in Heat and Mass Transfer 2017;85:12-22. https://doi.org/10.1016/j.icheatmasstransfer.2017.04.001.

[31] Sur UK. Graphene: A Rising Star on the Horizon of Materials Science. International Journal of Electrochemistry Volume 2012, Article ID 237689, 12 pages https://doi.org/10.1155/2012/237689

[32] Arshad A, Jabbal M, Yan Y, Reay D. A review on graphene based nanofluids: Preparation, characterization and applications. vol. 279. Elsevier B.V.; 2019. https://doi.org/10.1016/j.molliq.2019.01.153. 
[33] Le Ba T, Mahian O, Wongwises S, Szilágyi IM, Ba T Le, Mahian O, et al. Review on the recent progress in the preparation and stability of graphene-based nanofluids. Journal of Thermal Analysis and Calorimetry 2020;142:1145-72. https://doi.org/10.1007/s10973-020-09365-9.

[34] Bahiraei M, Heshmatian S. Graphene family nanofluids: A critical review and future research directions. Energy Conversion and Management 2019;196:1222-56. https://doi.org/10.1016/j.enconman.2019.06.076.

[35] Chouhan A, Mungse HP, Khatri OP. Surface chemistry of graphene and graphene oxide: A versatile route for their dispersion and tribological applications. Advances in Colloid and Interface Science 2020;283:102215. https://doi.org/10.1016/j.cis.2020.102215.

[36] Malekpour H, Ramnani P, Srinivasan S, Balasubramanian G, L. Nika D, Mulchandani A, et al. Thermal conductivity of graphene with defects induced by electron beam irradiation. Nanoscale 2016;8:14608-16. https://doi.org/10.1039/c6nr03470e.

[37] Borode AO, Ahmed NA, Olubambi PA. Surfactant-aided dispersion of carbon nanomaterials in aqueous solution. Physics of Fluids 2019;31:71301. https://doi.org/10.1063/1.5105380.

[38] Sarsam WS, Amiri A, Zubir MNM, Yarmand H, Kazi SN, Badarudin A. Stability and thermophysical properties of water-based nanofluids containing triethanolamine-treated graphene nanoplatelets with different specific surface areas. Colloids and Surfaces A: Physicochemical and Engineering Aspects 2016;500:17-31. https://doi.org/10.1016/j.colsurfa.2016.04.016.

[39] Zhou M, Xia G, Li J, Chai L, Zhou L, Mingzheng Z, et al. Analysis of factors influencing thermal conductivity and viscosity in different kinds of surfactant solutions. Experimental Thermal and Fluid Science 2012;36:22-9. https://doi.org/10.1016/j.expthermflusci.2011.07.014.

[40] Vallejo JP, Perez-Tavernier J, Cabaleiro D, Fernandez-Seara J, Lugo L, Pérez-Tavernier J, et al. Potential heat transfer enhancement of functionalized graphene nanoplatelet dispersions in a propylene glycol-water mixture. Thermophysical profile. The Journal of Chemical Thermodynamics 2018;123:174-84. https://doi.org/10.1016/j.jct.2018.04.007.

[41] Hamze S, Cabaleiro D, Estellé P. Graphene-based nanofluids: A comprehensive review about rheological behavior and dynamic viscosity. Journal of Molecular Liquids 2020;325:115207. https://doi.org/10.1016/j.molliq.2020.115207.

[42] Yang L, Xu J, Du K, Zhang X. Recent developments on viscosity and thermal conductivity of nanofluids. Powder Technol 2017;317:348-69. https://doi.org/10.1016/j.powtec.2017.04.061.

[43] Lin L, Peng H, Liu Z. Synthesis challenges for graphene industry. Nature Materials 2019;18:520-4. https://doi.org/10.1038/s41563-019-0341-4.

[44] Buzaglo M, Ruse E, Levy I, Nadiv R, Reuveni G, Shtein M, et al. Top-Down, Scalable Graphene Sheets Production: It Is All about the Precipitate. Chemistry of Materials 2017;29:9998-10006. https://doi.org/10.1021/acs.chemmater.7b03428.

[45] Kairi MI, Dayou S, Kairi NI, Abu Bakar S, Vigolo B, Mohamed AR, et al. Toward high production of graphene flakes-a review on recent developments in their synthesis methods and scalability. Journal of Materials Chemistry A 2018;6:15010-26. https://doi.org/10.1039/c8ta04255a.

[46] Hummers WS, Offeman RE. Preparation of Graphitic Oxide. Journal of the American Chemical Society 1958;80:1339. https://doi.org/10.1021/ja01539a017.

[47] Pei S, Cheng HM. The reduction of graphene oxide. Carbon 2012;50:3210-28. https://doi.org/10.1016/j.carbon.2011.11.010.

[48] Rasheed AK, Khalid M, Rashmi W, Gupta TCSM, Chan A. Graphene based nanofluids and nanolubricants - Review of recent developments. Renewable \& Sustainable Energy Reviews 2016;63:346-62. https://doi.org/10.1016/j.rser.2016.04.072.

[49] Sadeghinezhad E, Mehrali MMM, Saidur R, Mehrali MMM, Latibari ST, Akhiani AR, et al. A comprehensive review on graphene nanofluids: Recent research, development and applications. Energy Conversion and Management 2016;111:466-87. https://doi.org/10.1016/j.enconman.2016.01.004.

[50] Goodarzi M, Kherbeet AS, Afrand M, Sadeghinezhad E, Mehrali M, Zahedi P, et al. Investigation of heat transfer performance and friction factor of a counter-flow double-pipe 
heat exchanger using nitrogen-doped, graphene-based nanofluids. International Communications in Heat and Mass Transfer 2016;76:16-23.

https://doi.org/10.1016/j.icheatmasstransfer.2016.05.018.

[51] Cárdenas Contreras EM, Oliveira GA, Bandarra Filho EP. Experimental analysis of the thermohydraulic performance of graphene and silver nanofluids in automotive cooling systems. International Journal of Heat and Mass Transfer 2019;132:375-87. https://doi.org/10.1016/j.ijheatmasstransfer.2018.12.014.

[52] Brodie BC. on the Atomic Weight of Graphit. Royal Society of London 1858;149:423-9.

[53] K.S.Novoselov. Electric Field Effect in Atomically Thin Carbon Films. Medicina Clinica 2004;146:93-4. https://doi.org/10.1016/j.medcli.2015.04.005.

[54] Burghard M. Electronic and vibrational properties of chemically modified single-wall carbon nanotubes. Surface Science Reports 2005;58:1-109. https://doi.org/10.1016/j.surfrep.2005.07.001.

[55] Michael F. L.; De Volder, Sameh H.; Tawfick, Ray H.; Baughman, A. John ;Hart, De Volder MFL, Tawfick SH, et al. Carbon nanotubes: present and future commercial applications. Science (New York, NY) 2013;339:535-9. https://doi.org/10.1126/science.1222453.

[56] Castro E V., Novoselov KS, Morozov S V., Peres NMR, Dos Santos JMBL, Nilsson J, et al. Biased bilayer graphene: Semiconductor with a gap tunable by the electric field effect. Physical Review Letters 2007;99:8-11. https://doi.org/10.1103/PhysRevLett.99.216802.

[57] Geim AK, Novoselov KS. The rise of Graphene. Nature Materials 2007;6:183-91.

[58] Balandin AA, Ghosh S, Bao W, Calizo I, Teweldebrhan D, Miao F, et al. Superior thermal conductivity of single-layer graphene. Nano Letters 2008;8:902-7. https://doi.org/10.1021/nl0731872.

[59] Xu X, Pereira LFCC, Wang Y, Wu J, Zhang K, Zhao X, et al. Length-dependent thermal conductivity in suspended single-layer graphene. Nature Communications 2014;5:3689. https://doi.org/10.1038/ncomms4689.

[60] Bianco A, Cheng H-MM, Enoki T, Gogotsi Y, Hurt RH, Koratkar N, et al. All in the graphene family - A recommended nomenclature for two-dimensional carbon materials. Carbon 2013;65:1-6. https://doi.org/10.1016/j.carbon.2013.08.038.

[61] Wick P, Louw-Gaume AE, Kucki M, Krug HF, Kostarelos K, Fadeel B, et al. Classification framework for graphene-based materials. Angewandte Chemie - International Edition 2014;53:7714-8. https://doi.org/10.1002/anie.201403335.

[62] Zhu J, Childress AS, Karakaya M, Dandeliya S, Srivastava A, Lin Y, et al. Defect-Engineered Graphene for High-Energy- and High-Power-Density Supercapacitor Devices. Advanced Materials 2016;28:7185-92. https://doi.org/10.1002/adma.201602028.

[63] Dreyer DR, Park S, Bielawski CW, Ruoff RS. The chemistry of graphene oxide. Chemical Society Reviews 2010;39:228-40. https://doi.org/10.1039/b917103g.

[64] Zeng W, Tao X-MM, Lin S, Lee C, Shi D, Lam K ho, et al. Defect-engineered reduced graphene oxide sheets with high electric conductivity and controlled thermal conductivity for soft and flexible wearable thermoelectric generators. Nano Energy 2018;54:163-74. https://doi.org/10.1016/j.nanoen.2018.10.015.

[65] Kalluri A, Debnath D, Dharmadhikari B, Patra P. Graphene Quantum Dots: Synthesis and Applications. vol. 609. 1st ed. Elsevier Inc.; 2018. https://doi.org/10.1016/bs.mie.2018.07.002.

[66] Khan M, Tahir MN, Adil SF, Khan HU, Siddiqui MRH, Al-warthan AA, et al. Graphene based metal and metal oxide nanocomposites: synthesis, properties and their applications. Journal of Materials Chemistry A 2015;3:18753-808. https://doi.org/10.1039/C5TA02240A.

[67] Wang X, You H, Liu F, Li M, Wan L, Li S, et al. Large-scale synthesis of few-layered graphene using CVD. Chemical Vapor Deposition 2009;15:53-6. https://doi.org/10.1002/cvde.200806737.

[68] Lupina G, Kitzmann J, Costina I, Lukosius M, Wenger C, Wolff A, et al. Residual metallic contamination of transferred chemical vapor deposited graphene. ACS Nano 2015;9:4776-85. https://doi.org/10.1021/acsnano.5b01261. 
[69] Choucair M, Thordarson P, Stride JA. Gram-scale production of graphene based on solvothermal synthesis and sonication | Nature Nanotechnology. Nature Nanotechnology 2020;4:30-3. https://doi.org/10.1038/nnano.2008.365.

[70] Liang X, Chang ASP, Zhang Y, Harteneck BD, Choo H, Olynick DL, et al. Electrostatic force assisted exfoliation of prepatterned few-layer graphenes into device sites. Nano Letters 2009;9:467-72. https://doi.org/10.1021/nl803512z.

[71] Noroozi M, Zakaria A, Radiman S, Wahab ZA. Environmental synthesis of few layers graphene sheets using ultrasonic exfoliation with enhanced electrical and thermal properties. PLOS ONE 2016;11:1-17. https://doi.org/10.1371/journal.pone.0152699.

[72] Kairi MI, Khavarian M, Abu Bakar S, Vigolo B, Mohamed AR. Recent trends in graphene materials synthesized by CVD with various carbon precursors. Journal of Materials Science 2018;53:851-79. https://doi.org/10.1007/s10853-017-1694-1.

[73] Englert JM, Röhrl J, Schmidt CD, Graupner R, Hundhausen M, Hauke F, et al. Soluble graphene: Generation of aqueous graphene solutions aided by a perylenebisimide-based bolaamphiphile. Advanced Materials 2009;21:4265-9. https://doi.org/10.1002/adma.200901578.

[74] Hamze S, Berrada N, Cabaleiro D, Desforges A, Ghanbaja J, Gleize J, et al. Few-Layer Graphene-Based Nanofluids with Enhanced Thermal Conductivity. Nanomaterials 2020;10:1258. https://doi.org/10.3390/nano10071258.

[75] Bourlinos AB, Georgakilas V, Zboril R, Sterioti TA, Stubos AK. Liquid-Phase Exfoliation of Graphite Towards Solubilized Graphenes. Small 2009;5:1841-5. https://doi.org/10.1002/smll.200900242.

[76] Poh HL, Šaněk F, Ambrosi A, Zhao G, Sofer Z, Pumera M. Graphenes prepared by Staudenmaier, Hofmann and Hummers methods with consequent thermal exfoliation exhibit very different electrochemical properties. Nanoscale 2012;4:3515-22. https://doi.org/10.1039/c2nr30490b.

[77] Staudenmaier L. Verfahren zur Darstellung der Graphitsäure. Berichte Der Deutschen Chemischen Gesellschaft 1898;31:1481-7. https://doi.org/10.1002/cber.18980310237.

[78] Hofmann U, König E. Untersuchungen über Graphitoxyd. Zeitschrift für anorganische und allgemeine Chemie 1937;234:311-36. https://doi.org/10.1002/zaac.19372340405.

[79] Zaaba NI, Foo KL, Hashim U, Tan SJ, Liu WW, Voon CH. Synthesis of Graphene Oxide using Modified Hummers Method: Solvent Influence. Procedia Engineering 2017;184:469-77. https://doi.org/10.1016/j.proeng.2017.04.118.

[80] Shahriary L, Athawale A a. Graphene Oxide Synthesized by using Modified Hummers Approach. International Journal of Renewable Energy and Environmental Engineering 2014;02:58-63.

[81] Alam SN, Sharma N, Kumar L. Synthesis of Graphene Oxide (GO) by Modified Hummers Method and Its Thermal Reduction to Obtain Reduced Graphene Oxide ( $\mathrm{rGO})^{*}$. Graphene 2017;06:1-18. https://doi.org/10.4236/graphene.2017.61001.

[82] Kim C Bin, Lee J, Cho J, Goh M. Thermal conductivity enhancement of reduced graphene oxide via chemical defect healing for efficient heat dissipation. Carbon 2018;139:386-92. https://doi.org/10.1016/j.carbon.2018.07.008.

[83] Lee JH, Kang S, Jaworski J, Kwon KY, Seo ML, Lee JY, et al. Fluorescent composite hydrogels of metal-organic frameworks and functionalized graphene oxide. Chemistry - A European Journal 2012;18:765-9. https://doi.org/10.1002/chem.201102603.

[84] Kuila T, Mishra AK, Khanra P, Kim NH, Lee JH. Recent advances in the efficient reduction of graphene oxide and its application as energy storage electrode materials. Nanoscale 2013;5:52-71. https://doi.org/10.1039/c2nr32703a.

[85] Mohan VB, Brown R, Jayaraman K, Bhattacharyya D. Characterisation of reduced graphene oxide: Effects of reduction variables on electrical conductivity. Materials Science and Engineering B: Solid-State Materials for Advanced Technology 2015;193:49-60. https://doi.org/10.1016/j.mseb.2014.11.002.

[86] Sreeprasad TS, Berry V. How Do the Electrical Properties of Graphene Change with its Functionalization? Small 2013;9:341-50. https://doi.org/10.1002/smll.201202196. 
[87] Vinoth Kumar SHB, Muydinov R, Szyszka B. Plasma Assisted Reduction of Graphene Oxide Films. Nanomaterials (Basel) 2021;11. https://doi.org/10.3390/nano11020382.

[88] Cheng M, Yang R, Zhang L, Shi Z, Yang W, Wang D, et al. Restoration of graphene from graphene oxide by defect repair. Carbon 2012;50:2581-7.

https://doi.org/10.1016/j.carbon.2012.02.016.

[89] Renteria JD, Ramirez S, Malekpour H, Alonso B, Centeno A, Zurutuza A, et al. Strongly Anisotropic Thermal Conductivity of Free-Standing Reduced Graphene Oxide Films Annealed at High Temperature. Advanced Functional Materials 2015;25:4664-72. https://doi.org/10.1002/adfm.201501429.

[90] Shen X, Lin X, Jia J, Wang Z, Li Z, Kim J-K. Tunable thermal conductivities of graphene oxide by functionalization and tensile loading. Carbon 2014;80:235-45. https://doi.org/10.1016/j.carbon.2014.08.062.

[91] Mu X, Wu X, Zhang T, Go DB, Luo T. Thermal Transport in Graphene Oxide - From Ballistic Extreme to Amorphous Limit. Scientific Reports 2014;4:3909. https://doi.org/10.1038/srep03909.

[92] Zeng Y, Li T, Yao Y, Li T, Hu L, Marconnet A. Thermally Conductive Reduced Graphene Oxide Thin Films for Extreme Temperature Sensors. Advanced Functional Materials 2019;29:1901388. https://doi.org/10.1002/adfm.201901388.

[93] Balandin AA. Thermal properties of graphene and nanostructured carbon materials. Nature Materials 2011;10:569-81. https://doi.org/10.1038/nmat3064.

[94] Tian W, Li W, Yu W, Liu X. A review on lattice defects in graphene: Types generation effects and regulation. Micromachines 2017;8. https://doi.org/10.3390/mi8050163.

[95] Cai W, Moore AL, Zhu Y, Li X, Chen S, Shi L, et al. Thermal transport in suspended and supported monolayer graphene grown by chemical vapor deposition. Nano Letters 2010;10:1645-51. https://doi.org/10.1021/nl9041966.

[96] Balandin AA, Ghosh S, Nika DL, Pokatilov EP. Thermal Conduction in Suspended Graphene Layers. Fullerenes, Nanotubes and Carbon Nanostructures 2010;18:474-86. https://doi.org/10.1080/1536383X.2010.487785.

[97] Chen J, Yang C. Effects of grain dimensions and edge states on the thermal conductivity of graphene ribbons. Diamond and Related Materials 2020;108:107919. https://doi.org/10.1016/j.diamond.2020.107919.

[98] Jang W, Chen Z, Bao W, Lau CN, Dames C. Thickness-Dependent Thermal Conductivity of Encased Graphene and Ultrathin Graphite. Nano Lett 2010;10:3909-13. https://doi.org/10.1021/nl101613u.

[99] Pyun KR, Ko SH. Graphene as a material for energy generation and control: Recent progress in the control of graphene thermal conductivity by graphene defect engineering. Materials Today Energy 2019;12:431-42. https://doi.org/10.1016/j.mtener.2019.04.008.

[100] Feng T, Ruan X, Ye Z, Cao B. Spectral phonon mean free path and thermal conductivity accumulation in defected graphene: The effects of defect type and concentration. Physical Review B 2015;91:224301. https://doi.org/10.1103/PhysRevB.91.224301.

[101] Lee BS. Effect of phonon scattering by substitutional and structural defects on thermal conductivity of 2D graphene. Journal of Physics: Condensed Matter 2018;30:295302. https://doi.org/10.1088/1361-648X/aacabe.

[102] Yang H, Tang Y, Gong J, Liu Y, Wang X, Zhao Y, et al. Influence of doped nitrogen and vacancy defects on the thermal conductivity of graphene nanoribbons. Journal of Molecular Modeling 2013;19:4781-8. https://doi.org/10.1007/s00894-013-1937-2.

[103] Zhang X, Zhang J, Yang M. The effects of Stone-Wales defects on the thermal properties of bilayer armchair graphene nanoribbons. RSC Advances 2020;10:19254-7. https://doi.org/10.1039/DORA02480E.

[104] Huang P, Zhu H, Jing L, Zhao Y, Gao X. Graphene Covalently Binding Aryl Groups: Conductivity Increases Rather than Decreases. ACS Nano 2011;5:7945-9.

https://doi.org/10.1021/nn2023232. 
[105] Estellé P, Halelfadl S, Maré T. Lignin as dispersant for water-based carbon nanotubes nanofluids: Impact on viscosity and thermal conductivity. International Communications in Heat and Mass Transfer 2014;57:8-12.

https://doi.org/10.1016/j.icheatmasstransfer.2014.07.012.

[106] Sarsam WS, Amiri A, Kazi SN, Badarudin A. Stability and thermophysical properties of noncovalently functionalized graphene nanoplatelets nanofluids. Energy Conversion and Management 2016;116:101-11. https://doi.org/10.1016/j.enconman.2016.02.082.

[107] Yu W, Xie H, Chen L, Li Y. Investigation on the thermal transport properties of ethylene glycolbased nanofluids containing copper nanoparticles. Powder Technology 2010;197:218-21. https://doi.org/10.1016/j.powtec.2009.09.016.

[108] Tavman I, Turgut A. An Investigation on Thermal Conductivity and Viscosity of Water Based Nanofluids. In: Kakaç S, Kosoy B, Li D, Pramuanjaroenkij A, editors., Springer Netherlands; 2010, p. 139-62. https://doi.org/10.1007/978-90-481-9029-4_8.

[109] Hiroshi Akoh, Yukihiro Tsukasaki SY and AT. Magnetic Properties of Ferromagnetic Ultrafine Particles Prepared By Vacuum. Journal of Crystal Growth 1978;45:495-500.

[110] Mortazavi SZ, Parvin P, Reyhani A. Fabrication of graphene based on Q-switched Nd:YAG laser ablation of graphite target in liquid nitrogen. Laser Physics Letters 2012;9:547-52. https://doi.org/10.7452/lapl.201210033.

[111] Dhinesh Kumar D, Valan Arasu A. A comprehensive review of preparation, characterization, properties and stability of hybrid nanofluids. Renewable and Sustainable Energy Reviews 2018;81:1669-89. https://doi.org/10.1016/j.rser.2017.05.257.

[112] Sadri R, Ahmadi G, Togun H, Dahari M, Kazi SN, Sadeghinezhad E, et al. An experimental study on thermal conductivity and viscosity of nanofluids containing carbon nanotubes. Nanoscale Research Letters 2014;9:4-13. https://doi.org/10.1186/1556-276X-9-151.

[113] R. B. A brief Account of Microscopical observations made in the Months of June, July and August, 1827, on the Particles contained in the Pollen of Plants. 1827;7:1-16.

[114] Vallejo JP, Álvarez-Regueiro E, Cabaleiro D, Fernández-Seara J, Fernández J, Lugo L. Functionalized graphene nanoplatelet nanofluids based on a commercial industrial antifreeze for the thermal performance enhancement of wind turbines. Applied Thermal Engineering 2019;152:113-25. https://doi.org/10.1016/j.applthermaleng.2019.02.046.

[115] Baby TT, Ramaprabhu S. Enhanced convective heat transfer using graphene dispersed nanofluids. Nanoscale Research Letters 2011;6:289. https://doi.org/10.1186/1556-276X-6-289.

[116] Baby TT, Ramaprabhu S. Investigation of thermal and electrical conductivity of graphene based nanofluids. Journal of Applied Physics 2010;108. https://doi.org/10.1063/1.3516289.

[117] Lee D, Kim JW, Kim BG. A new parameter to control heat transport in nanofluids: Surface charge state of the particle in suspension. Journal of Physical Chemistry B 2006;110:4323-8. https://doi.org/10.1021/jp057225m.

[118] Agarwal DK, Vaidyanathan A, Sunil Kumar S. Experimental investigation on thermal performance of kerosene-graphene nanofluid. Experimental Thermal and Fluid Science 2016;71:126-37. https://doi.org/10.1016/j.expthermflusci.2015.10.028.

[119] Ahammed N, Asirvatham LG, Titus J, Bose JR, Wongwises S. Measurement of thermal conductivity of graphene-water nanofluid at below and above ambient temperatures. International Communications in Heat and Mass Transfer 2016;70:66-74. https://doi.org/10.1016/j.icheatmasstransfer.2015.11.002.

[120] Akbari A, Fazel SAA, Maghsoodi S, Kootenaei AS, Alavi Fazel SA, Maghsoodi S, et al. Thermophysical and stability properties of raw and functionalization of graphene nanoplatelets-based aqueous nanofluids. Journal of Dispersion Science and Technology 2019;40:17-24. https://doi.org/10.1080/01932691.2018.1462713.

[121] Cabaleiro D, Colla L, Barison S, Lugo L, Fedele L, Bobbo S. Heat Transfer Capability of (Ethylene Glycol + Water)-Based Nanofluids Containing Graphene Nanoplatelets: Design and Thermophysical Profile. Nanoscale Research Letters 2017;12:53. https://doi.org/10.1186/s11671-016-1806-x. 
[122] Zhongpan Cai MT and GZ. Experimental Study on the Flow and Heat Transfer of GrapheneBased Lubricants in a Horizontal Tube. Processes 2020;35:67-73. https://doi.org/10.16146/j.cnki.rndlgc.2020.11.010.

[123] Nika DL, Askerov AS, Balandin AA. Anomalous Size Dependence of the Thermal Conductivity of Graphene Ribbons. Nano Letters 2012;12:3238-44. https://doi.org/10.1021/nl301230g.

[124] Chen L, Xu C, Liu J, Fang X, Zhang Z. Optical absorption property and photo-thermal conversion performance of graphene oxide/water nanofluids with excellent dispersion stability. Solar Energy 2017;148:17-24. https://doi.org/10.1016/j.solener.2017.03.073.

[125] Chen L, Liu J, Fang X, Zhang Z. Reduced graphene oxide dispersed nanofluids with improved photo thermal conversion performance for direct absorption solar collectors. Solar Energy Materials and Solar Cells 2017;163:125-33. https://doi.org/10.1016/j.solmat.2017.01.024.

[126] Esfahani MR, Languri EM. Exergy analysis of a shell-and-tube heat exchanger using graphene oxide nanofluids. Experimental Thermal and Fluid Science 2017;83:100-6. https://doi.org/10.1016/j.expthermflusci.2016.12.004.

[127] Gao Y, Wang H, Sasmito AP, Mujumdar AS. Measurement and modeling of thermal conductivity of graphene nanoplatelet water and ethylene glycol base nanofluids. International Journal of Heat and Mass Transfer 2018;123:97-109. https://doi.org/10.1016/j.ijheatmasstransfer.2018.02.089.

[128] Ghozatloo A, Rashidi A, Shariaty-Niassar M. Convective heat transfer enhancement of graphene nanofluids in shell and tube heat exchanger. Experimental Thermal and Fluid Science 2014;53:136-41. https://doi.org/10.1016/j.expthermflusci.2013.11.018.

[129] Ghozatloo A, Shariaty-Niasar M, Rashidi AM. Preparation of nanofluids from functionalized Graphene by new alkaline method and study on the thermal conductivity and stability. International Communications in Heat and Mass Transfer 2013;42:89-94. https://doi.org/10.1016/j.icheatmasstransfer.2012.12.007.

[130] Goharshadi EK, Niyazi Z, Shafaee M, Moghaddam MB, Ludwig R, Namayandeh-Jorabchi M. Transport properties of graphene quantum dots in glycerol and distilled water. Journal of Molecular Liquids 2017;241:831-8. https://doi.org/10.1016/j.molliq.2017.06.089.

[131] Sen Gupta S, Manoj Siva V, Krishnan S, Sreeprasad TS, Singh PK, Pradeep T, et al. Thermal conductivity enhancement of nanofluids containing graphene nanosheets. Journal of Applied Physics 2011;110:84302. https://doi.org/10.1063/1.3650456.

[132] Hadadian M, Goharshadi EK, Youssefi A. Electrical conductivity, thermal conductivity, and rheological properties of graphene oxide-based nanofluids. Journal of Nanoparticle Research 2014;16:2788. https://doi.org/10.1007/s11051-014-2788-1.

[133] Hajjar Z, Rashidi A morad, Ghozatloo A. Enhanced thermal conductivities of graphene oxide nanofluids. International Communications in Heat and Mass Transfer 2014;57:128-31. https://doi.org/10.1016/j.icheatmasstransfer.2014.07.018.

[134] Ijam A, Saidur R, Ganesan P, Moradi Golsheikh A. Stability, thermo-physical properties, and electrical conductivity of graphene oxide-deionized water/ethylene glycol based nanofluid. International Journal of Heat and Mass Transfer 2015;87:92-103. https://doi.org/10.1016/j.ijheatmasstransfer.2015.02.060.

[135] Iranmanesh S, Mehrali M, Sadeghinezhad E, Ang BC, Ong HC, Esmaeilzadeh A. Evaluation of viscosity and thermal conductivity of graphene nanoplatelets nanofluids through a combined experimental-statistical approach using respond surface methodology method. International Communications in Heat and Mass Transfer 2016;79:74-80. https://doi.org/10.1016/j.icheatmasstransfer.2016.10.004.

[136] Iranmanesh S, Ong HC, Ang BC, Sadeghinezhad E, Esmaeilzadeh A, Mehrali M. Thermal performance enhancement of an evacuated tube solar collector using graphene nanoplatelets nanofluid. Journal of Cleaner Production 2017;162:121-9. https://doi.org/10.1016/j.jclepro.2017.05.175.

[137] khosrojerdi S, Lavasani AM, Vakili M. Experimental study of photothermal specifications and stability of graphene oxide nanoplatelets nanofluid as working fluid for low-temperature 
Direct Absorption Solar Collectors (DASCs). Solar Energy Materials and Solar Cells 2017;164:32-9. https://doi.org/10.1016/j.solmat.2017.02.007.

[138] Kole M, Dey TK. Investigation of thermal conductivity, viscosity, and electrical conductivity of graphene based nanofluids. Journal of Applied Physics 2013;113:84307. https://doi.org/10.1063/1.4793581.

[139] Lee G-JJ, Rhee CK. Enhanced thermal conductivity of nanofluids containing graphene nanoplatelets prepared by ultrasound irradiation. Journal of Materials Science 2014;49:150611. https://doi.org/10.1007/s10853-013-7831-6.

[140] Liu J, Wang F, Zhang L, Fang X, Zhang Z. Thermodynamic properties and thermal stability of ionic liquid-based nanofluids containing graphene as advanced heat transfer fluids for medium-to-high-temperature applications. Renewable Energy 2014;63:519-23. https://doi.org/10.1016/j.renene.2013.10.002.

[141] Liu J, Xu C, Chen LL, Fang X, Zhang Z. Preparation and photo-thermal conversion performance of modified graphene/ionic liquid nanofluids with excellent dispersion stability. Solar Energy Materials and Solar Cells 2017;170:219-32. https://doi.org/10.1016/j.solmat.2017.05.062.

[142] Ma W, Yang F, Shi J, Wang F, Zhang Z, Wang S. Silicone based nanofluids containing functionalized graphene nanosheets. Colloids and Surfaces A: Physicochemical and Engineering Aspects 2013;431:120-6. https://doi.org/10.1016/j.colsurfa.2013.04.031.

[143] Mehrali MM, Sadeghinezhad E, Rosen MA, Akhiani AR, Tahan Latibari S, Mehrali MM, et al. Experimental investigation of thermophysical properties, entropy generation and convective heat transfer for a nitrogen-doped graphene nanofluid in a laminar flow regime. Advanced Powder Technology 2016;27:717-27. https://doi.org/10.1016/j.apt.2016.02.028.

[144] Mehrali MM, Sadeghinezhad E, Rosen MA, Tahan Latibari S, Mehrali MM, Metselaar HSC, et al. Effect of specific surface area on convective heat transfer of graphene nanoplatelet aqueous nanofluids. Experimental Thermal and Fluid Science 2015;68:100-8. https://doi.org/10.1016/j.expthermflusci.2015.03.012.

[145] Mehrali MM, Sadeghinezhad E, Rosen MA, Akhiani AR, Tahan Latibari S, Mehrali MM, et al. Heat transfer and entropy generation for laminar forced convection flow of graphene nanoplatelets nanofluids in a horizontal tube. International Communications in Heat and Mass Transfer 2015;66:23-31. https://doi.org/10.1016/j.icheatmasstransfer.2015.05.007.

[146] Mehrali MM, Sadeghinezhad E, Akhiani AR, Latibari ST, Talebian S, Dolatshahi-Pirouz A, et al. An ecofriendly graphene-based nanofluid for heat transfer applications. Journal of Cleaner Production 2016;137:555-66. https://doi.org/10.1016/j.jclepro.2016.07.136.

[147] Mehrali MM, Sadeghinezhad E, Tahan Latibari S, Mehrali MM, Togun H, Zubir MNMM, et al. Preparation, characterization, viscosity, and thermal conductivity of nitrogen-doped graphene aqueous nanofluids. Journal of Materials Science 2014;49:7156-71. https://doi.org/10.1007/s10853-014-8424-8.

[148] Mehrali MM, Sadeghinezhad E, Latibari ST, Kazi SN, Mehrali MM, Zubir MNBM, et al. Investigation of thermal conductivity and rheological properties of nanofluids containing graphene nanoplatelets. Nanoscale Research Letters 2014;9:15. https://doi.org/10.1186/1556-276X-9-15.

[149] Naghash A, Sattari S, Rashidi A. Experimental assessment of convective heat transfer coefficient enhancement of nanofluids prepared from high surface area nanoporous graphene. International Communications in Heat and Mass Transfer 2016;78:127-34. https://doi.org/10.1016/j.icheatmasstransfer.2016.09.004.

[150] Naveen NS, Kishore PS. Experimental investigation on heat transfer parameters of an automotive car radiator using graphene/water-ethylene glycol coolant. Journal of Dispersion Science and Technology 2020;0:1-13. https://doi.org/10.1080/01932691.2020.1840999.

[151] Sadeghinezhad E, Mehrali MM, Rosen MA, Akhiani AR, Tahan Latibari S, Mehrali MM, et al. Experimental investigation of the effect of graphene nanofluids on heat pipe thermal performance. Applied Thermal Engineering 2016;100:775-87. https://doi.org/10.1016/j.applthermaleng.2016.02.071. 
[152] Sadeghinezhad E, Akhiani AR, Metselaar HSC, Tahan Latibari S, Mehrali M, Mehrali M. Parametric study on the thermal performance enhancement of a thermosyphon heat pipe using covalent functionalized graphene nanofluids. Applied Thermal Engineering 2020;175:115385. https://doi.org/10.1016/j.applthermaleng.2020.115385.

[153] Sadeghinezhad E, Togun H, Mehrali M, Sadeghi Nejad P, Tahan Latibari S, Abdulrazzaq T, et al. An experimental and numerical investigation of heat transfer enhancement for graphene nanoplatelets nanofluids in turbulent flow conditions. International Journal of Heat and Mass Transfer 2015;81:41-51. https://doi.org/10.1016/j.ijheatmasstransfer.2014.10.006.

[154] Sadri R, Hosseini M, Kazi SN, Bagheri S, Zubir N, Ahmadi G, et al. A novel, eco-friendly technique for covalent functionalization of graphene nanoplatelets and the potential of their nanofluids for heat transfer applications. Chemical Physics Letters 2017;675:92-7. https://doi.org/10.1016/j.cplett.2017.02.077.

[155] Sadri R, Hosseini M, Kazi SN, Bagheri S, Ahmed SM, Ahmadi G, et al. Study of environmentally friendly and facile functionalization of graphene nanoplatelet and its application in convective heat transfer. Energy Conversion and Management 2017;150:26-36. https://doi.org/10.1016/j.enconman.2017.07.036.

[156] Sadri R, Hosseini M, Kazi SN, Bagheri S, Abdelrazek AH, Ahmadi G, et al. A facile, bio-based, novel approach for synthesis of covalently functionalized graphene nanoplatelet nanocoolants toward improved thermo-physical and heat transfer properties. Journal of Colloid and Interface Science 2018;509:140-52. https://doi.org/10.1016/j.jcis.2017.07.052.

[157] Sedaghat F, Yousefi F. Synthesizes, characterization, measurements and modeling thermal conductivity and viscosity of graphene quantum dots nanofluids. Journal of Molecular Liquids 2019;278:299-308. https://doi.org/10.1016/j.molliq.2019.01.073.

[158] Selvam C, Mohan Lal D, Harish S. Enhanced heat transfer performance of an automobile radiator with graphene based suspensions. Applied Thermal Engineering 2017;123:50-60. https://doi.org/10.1016/j.applthermaleng.2017.05.076.

[159] Selvam C, Lal DM, Harish S, Mohan Lal D, Harish S, Lal DM, et al. Thermal conductivity and specific heat capacity of water-ethylene glycol mixture-based nanofluids with graphene nanoplatelets. Journal of Thermal Analysis and Calorimetry 2017;129:947-55. https://doi.org/10.1007/s10973-017-6276-6.

[160] Selvam C, Lal DM, Harish S. Thermal conductivity enhancement of ethylene glycol and water with graphene nanoplatelets. Thermochimica Acta 2016;642:32-8. https://doi.org/10.1016/j.tca.2016.09.002.

[161] Shazali SS, Rozali S, Amiri A, Zubir MNM, Sabri MFM, Zabri MZ. Evaluation on stability and thermophysical performances of covalently functionalized graphene nanoplatelets with xylitol and citric acid. Materials Chemistry and Physics 2018;212:363-71. https://doi.org/10.1016/j.matchemphys.2018.03.040.

[162] Sudeep PM, Taha-Tijerina J, Ajayan PM, Narayanan TN, Anantharaman MR. Nanofluids based on fluorinated graphene oxide for efficient thermal management. Rsc Advances 2014;4:24887-92. https://doi.org/10.1039/c4ra00843j.

[163] Tahani M, Vakili M, Khosrojerdi S. Experimental evaluation and ANN modeling of thermal conductivity of graphene oxide nanoplatelets/deionized water nanofluid. International Communications in Heat and Mass Transfer 2016;76:358-65. https://doi.org/10.1016/j.icheatmasstransfer.2016.06.003.

[164] Vakili M, Hosseinalipour SM, Delfani S, Khosrojerdi S. Photothermal properties of graphene nanoplatelets nanofluid for low-temperature direct absorption solar collectors. Solar Energy Materials and Solar Cells 2016;152:187-91. https://doi.org/10.1016/j.solmat.2016.01.038.

[165] Anin Vincely D, Natarajan E. Experimental investigation of the solar FPC performance using graphene oxide nanofluid under forced circulation. Energy Conversion and Management 2016;117:1-11. https://doi.org/10.1016/j.enconman.2016.03.015. 
[166] Wang F, Han L, Zhang Z, Fang X, Shi J, Ma W. Surfactant-free ionic liquid-based nanofluids with remarkable thermal conductivity enhancement at very low loading of graphene. Nanoscale Research Letters 2012;7:314. https://doi.org/10.1186/1556-276X-7-314.

[167] Yang L, Ji W, Zhang Z, Jin X. Thermal conductivity enhancement of water by adding graphene Nano-sheets: Consideration of particle loading and temperature effects. International Communications in Heat and Mass Transfer 2019;109:104353. https://doi.org/10.1016/j.icheatmasstransfer.2019.104353.

[168] Yarmand H, Gharehkhani S, Shirazi SFS, Amiri A, Alehashem MS, Dahari M, et al. Experimental investigation of thermo-physical properties, convective heat transfer and pressure drop of functionalized graphene nanoplatelets aqueous nanofluid in a square heated pipe. Energy Conversion and Management 2016;114:38-49. https://doi.org/10.1016/j.enconman.2016.02.008.

[169] Yu W, Xie H, Chen W. Experimental investigation on thermal conductivity of nanofluids containing graphene oxide nanosheets. Journal of Applied Physics 2010;107:94317. https://doi.org/10.1063/1.3372733.

[170] Yu W, Xie H, Bao D. Enhanced thermal conductivities of nanofluids containing graphene oxide nanosheets. Nanotechnology 2010;21:55705. https://doi.org/10.1088/09574484/21/5/055705.

[171] Yu W, Xie H, Wang XX, Wang XX. Significant thermal conductivity enhancement for nanofluids containing graphene nanosheets. Physics Letters A 2011;375:1323-8. https://doi.org/10.1016/j.physleta.2011.01.040.

[172] Zhang H, Wang S, Lin Y, Feng M, Wu Q. Stability, thermal conductivity, and rheological properties of controlled reduced graphene oxide dispersed nanofluids. Applied Thermal Engineering 2017;119:132-9. https://doi.org/10.1016/j.applthermaleng.2017.03.064.

[173] Zhou Y, Cui X, Weng J, Shi S, Han H, Chen C. Experimental investigation of the heat transfer performance of an oscillating heat pipe with graphene nanofluids. Powder Technology 2018;332:371-80. https://doi.org/10.1016/j.powtec.2018.02.048.

[174] Hussein OA, Habib K, Saidur R, Muhsan AS, Shahabuddin S, Alawi OA. The influence of covalent and non-covalent functionalization of GNP based nanofluids on its thermophysical, rheological and suspension stability properties. RSC Adv 2019;9:38576-89. https://doi.org/10.1039/C9RA07811H.

[175] Wang $X$, Zhu $D$, yang $S$. Investigation of $\mathrm{pH}$ and SDBS on enhancement of thermal conductivity in nanofluids. Chemical Physics Letters 2009;470:107-11. https://doi.org/10.1016/j.cplett.2009.01.035.

[176] Yang L, Chen X, Xu M, Du K. Roles of surfactants and particle shape in the enhanced thermal conductivity of TiO2 nanofluids. AIP Advances 2016;6:095104. https://doi.org/10.1063/1.4962659.

[177] Azizighannad S, Mitra S. Stepwise Reduction of Graphene Oxide (GO) and Its Effects on Chemical and Colloidal Properties. Scientific Reports 2018;8:10083. https://doi.org/10.1038/s41598-018-28353-6.

[178] Warner JH, Lin Y-C, He K, Koshino M, Suenaga K. Atomic Level Spatial Variations of Energy States along Graphene Edges. Nano Letters 2014;14:6155-9. https://doi.org/10.1021/nl5023095. 